\title{
Density functional dependence of molecular geometries in lanthanide(III) complexes relevant to bioanalytical and biomedical applications
}

\author{
Adrián Roca-Sabio, Martín Regueiro-Figueroa, David Esteban-Gómez, Andrés de Blas, Teresa \\ $\underline{\text { Rodríguez-Blas, }} \underline{\text { Carlos Platas-Iglesias }}$
}

Departamento de Química Fundamental, Facultad de Ciencias, Universidade da Coruña, Campus da Zapateira-Rúa da Fraga 10, 15008 A Coruña, Spain

Computational and Theoretical Chemistry, volume 999, pages 93-104, 01 November 2012

Received 30 April 2012, revised 26 July 2012, accepted 15 August 2012, available online 23 August 2012

\section{How to cite:}

Density Functional Dependence of Molecular Geometries in Lanthanide(III) Complexes Relevant to Bioanalytical and Biomedical Applications. Adrián Roca-Sabio, Martín Regueiro-Figueroa, David Esteban-Gómez, Andrés de Blas, Teresa Rodríguez-Blas, and Carlos Platas-Iglesias. Computational and Theoretical Chemistry 2012 999, 93-104. DOI: 10.1016/j.comptc.2012.08.020.

(C) 2012. This manuscript version is made available under the CC Attribution-NonCommercialNoDerivatives 4.0 International license: http://creativecommons.org/licenses/by-nc-nd/4.0.

\begin{abstract}
A set of 15 lanthanide-containing model systems was used to evaluate the performance of 15 commonly available density functionals (SVWN, SPL, BLYP, G96LYP, mPWLYP, B3LYP, BH\&HLYP, B3PW91, BB95, mPWB95, TPSS, TPSSh, M06, CAM-B3LYP and wB97XD) in geometry determination, benchmarked against MP2 calculations. The best agreement between DFT optimized geometries and those obtained from MP2 calculations is provided by meta-GGA and hybrid meta-GGA functionals. The use of hybrid-GGA functionals such as BH\&HLYP and B3PW91 also provide reasonably good results, while B3LYP provides an important overestimation of the metal-ligand bonds. The performance of different basis sets to describe the ligand(s) atoms, as well as the use of large-core (LC) RECPs and small-core (SC) RECPs, has been also assessed. Our calculations show that SCRECP calculations provide somewhat shorter

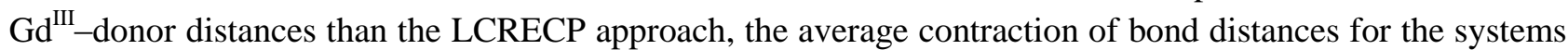
investigated amounting to $0.033 \AA$. However, geometry optimizations with the SCRECP (in combination with the mPWB95 functional and the 6-31G(d) basis set for the ligand atoms) take about 15 times longer than the LC counterparts, and about four times longer than MP2/LCRECP/6-31G(d) calculations. The 631G(d), 6-311G(d), 6-311G(d,p) or cc-pVDZ basis sets, in combination with LCRECPs, appear to offer an adequate balance between accuracy and computational cost for the description of molecular geometries of $\mathrm{Ln}^{\mathrm{III}}$ complexes. Electronic energies calculated with the the cc-pVxZ family ( $\left.\mathrm{x}=\mathrm{D}-6\right)$ indicate a relative fast convergence to the complete basis set (CBS) limit with basis set size. The inclusion of bulk solvent effects (IEFPCM) was shown to provoke an important impact on the calculated geometries, particularly on the metal-nitrogen distances. Calculations performed on lanthanide complexes relevant for practical applications confirmed the important effect of the solvent on the calculated geometries.
\end{abstract}

\footnotetext{
*arlos.platas.iglesias@udc.es
} 
Keywords: lanthanides; density functional calculations; MRI contrast agents; solvent effects; effective core potentials; f-Elements

\section{Introduction}

Lanthanide coordination chemistry in aqueous solution has experienced a fast development during the last 20 years due to the successful biomedical application of lanthanide chelates both in diagnostics and therapy ${ }^{[1-}$ 10]. Indeed, gadolinium(III) complexes with poly(aminocarboxylate) ligands attract considerably interest since they are commonly used as contrast agents in magnetic resonance imaging (MRI ${ }^{[2-6]}$. Furthermore, luminescent lanthanide complexes offer exceptional photophysical properties that find applications in different fields such as biomedical analyses and imaging ${ }^{[11,12]}$. Lanthanide(III) ( $\mathrm{Ln}^{\mathrm{III}}$ ) complexes for bioanalytical or biomedical applications should possess a high thermodynamic and/or kinetic stability under physiological conditions, which can be achieved by complexation of the metal ion with poly(aminocarboxylates) or other ligands that prevent the release of the toxic free $\mathrm{Ln}^{\mathrm{III}}$ ion ${ }^{[13,14]}$. The experimental work performed in $\mathrm{Ln}^{\text {III }}$ coordination compounds relevant for biomedical applications provides a plethora of information about their solid-state and solution structures and physicochemical properties. However, a relatively limited number of theoretical investigations performed on this kind of systems have been reported in the literature, which can be partially ascribed to the difficulties associated to the quantum chemical treatment of $\mathrm{Ln}^{\mathrm{III}}$ complexes, i.e. the presence of open shell $4 \mathrm{f}$ electrons, the treatment of relativistic effects, or the preference of $\mathrm{Ln}^{\mathrm{III}}$ ions for high coordination numbers (typically $\left.8-9\right)^{[15]}$.

Due to their specific applications, the characterization of $\mathrm{Ln}^{\mathrm{III}}$ complexes relevant as MRI contrast agents or luminescent probes requires the investigation of their properties in solution. The solid state structures of many $\mathrm{Ln}^{\mathrm{III}}$ complexes have been investigated by using X-ray crystallography. However, the structures determined in the solid state do not necessarily reflect their solution structures. Direct information on the solution structure of $\mathrm{Ln}^{\mathrm{III}}$ complexes can be obtained from extended X-ray absorption fine structure (EXAFS) spectroscopy ${ }^{[16,17]}$. However, a limited number of research groups have access to this technique, which has been applied so far to a relatively small number of systems. On the contrary, theoretical calculations may provide direct information on the structure and dynamics of $\mathrm{Ln}^{\mathrm{III}}$ complexes at the molecular level. The solution structure of $\mathrm{Ln}^{\mathrm{III}}$ complexes has been explored by using molecular mechanics (MM) methods ${ }^{[18-20]}$, semiempirical ${ }^{[21-25]}$ and $\mathrm{HF}^{[26-32]}$ calculations. More recently, density functional theory (DFT) calculations have been successfully applied to investigate the structure and properties of different lanthanide(III) coordination compounds ${ }^{[33]}$.

It has been shown that the local spin density approximation (LSDA) including spin-orbit corrections provides ionization potentials close to the experimental values for lanthanide atoms ${ }^{[34]}$. However, the electronic description becomes less accurate in molecular calculations, which often predict too short Lnligand bonds and too high binding energies ${ }^{[35]}$. Different functionals that use generalized gradient approximation (GGA) such as BLYP, or BP86 have been successfully used for describing lanthanide complexes, yet hybrid functionals such as B3LYP are often the functionals of choice within computational lanthanide chemistry ${ }^{[36-40]}$. An evaluation of different GGA and hybrid functionals on the $\mathrm{LnF}(\mathrm{Ln}=\mathrm{Nd}, \mathrm{Eu}$, $\mathrm{Gd}, \mathrm{Yb}$ ) and $\mathrm{YbH}$ systems showed that B3LYP and BP86 functionals give very similar geometries, while BLYP calculations deviate slightly more from the experimental results ${ }^{[41]}$. B3LYP was also shown to provide bond strengths in closer agreement to the experimental values than BLYP and BP86 ${ }^{[41]}$. A detailed investigation of the structural and thermodynamic features of $\mathrm{Ln}^{\mathrm{III}}$ aqua-ions has been recently reported. The structural parameters calculated for $\left[\mathrm{Ln}\left(\mathrm{H}_{2} \mathrm{O}\right)_{8}\right]^{3+}(\mathrm{Ln}=\mathrm{La}$ or $\mathrm{Lu})$ indicated also overbinding when using LSDA functionals ${ }^{[42]}$. Among the functionals tested in these studies the meta-GGA TPSS functional provided the closest structural agreement with experimental results, while the performance of the hybrid B3LYP functional was also reasonable ${ }^{[43]}$. Analogous calculations performed on the $\left[\mathrm{Ce}\left(\mathrm{H}_{2} \mathrm{O}\right)_{9}\right]^{3+}$ and $\left[\mathrm{Ce}\left(\mathrm{H}_{2} \mathrm{O}\right)_{8}\right]^{3+}$ 
species led to a similar conclusion ${ }^{[44]}$. In a series of recent papers, we used calculations based on the hybrid B3LYP functional to investigate the solution structure and dynamics of different $\mathrm{Ln}^{\mathrm{III}}$ complexes with both acyclic and macrocyclic ligands ${ }^{[45-53]}$. However, a detailed investigation on the performance of different density functionals in geometry determination of $\mathrm{Ln}^{\mathrm{III}}$ complexes is still lacking.

In this study we evaluate the performance of 15 different commonly available DFT functionals, benchmarked against MP2 calculations, in the determination of the geometries of model $\mathrm{Ln}^{\mathrm{III}}$ complexes. The effect of the basis set used for the description of the lanthanide and the ligand atoms on the calculated geometries has been also investigated. Furthermore, we have also evaluated the effect of the solvent (water) on the molecular geometries by using the polarizable continuum model (PCM). Finally, the effect of the DFT functional and inclusion of solvent effects on the molecular geometries of different $\mathrm{Ln}^{\mathrm{III}}$ complexes relevant for practical applications has been also analyzed.

\section{Computational methods}

All calculations were performed employing the Gaussian 09 package (Revision A.02) ${ }^{[54]}$. Full geometry optimizations were performed at the HF, second-order Møller-Plesset perturbation theory (MP2) and DFT levels. In the latter calculations we tested different functionals selected to include representatives of each of major classes: LSDA (SVWN ${ }^{[55,56]}$ and SPL $\left.{ }^{[57]}\right)$, GGA (BLYP, ${ }^{[58,59]}$ G96LYP ${ }^{[59-61]}$, mPWLYP ${ }^{[59,62]}$ ), hybridGGA, including the most popular functional $\left(\mathrm{B} 3 \mathrm{LYP}^{[59,63]}\right.$ ) as well as $\mathrm{BH} \& \mathrm{HLYP}^{[64]}$ and $\mathrm{B} 3 \mathrm{PW} 91^{[63,65]}$ ), meta-GGA (BB95 ${ }^{[58,66]} \mathrm{mPWB}^{[62]} \mathrm{TPSS}^{[67]}$ ), and $\mathrm{TPSSh}^{[67]}$ and M06 ${ }^{[68]}$ representing two lines of development of hybrid meta-GGAs. Additionally, we have also investigated the performance of two density functionals that include long-range corrections: the CAM-B3LYP functional of Handy and coworkers ${ }^{[69]}$ and wB97XD functional of Head-Gordon et al., which includes empirical dispersion and long-range corrections ${ }^{[70]}$. No symmetry constraints have been imposed during the optimizations. The default values for the integration grid (75 radial shells and 302 angular points) and the SCF energy convergence criteria $\left(10^{-8}\right)$ were used. The stationary points found on the potential energy surfaces as a result of the geometry optimizations have been tested to represent energy minima rather than saddle points via frequency analysis.

An important issue in the computational treatment of $\mathrm{Ln}^{\mathrm{III}}$ complexes and other systems containing heavy elements is the adequate treatment of relativistic effects ${ }^{[71]}$. The most widely used approximation to deal with the problems of quantum chemical treatment of lanthanides is the relativistic effective core potential (RECP) approach, in which only the chemically relevant valence electrons are treated explicitly and relativistic effects are implicitly accounted for by a proper adjustment of free parameters in the valence model Hamiltonian $^{[72]}$. The RECP approach also serves to decrease the computational requirements, so that calculations on relatively large lanthanide(III) complexes become feasible. In this work we employed the energy-consistent RECPs and associated basis sets of Dolg and coworkers ${ }^{[73-77]}$, for which two different core definitions have been developed: "large-core", in which the $4 \mathrm{f}$ electrons are included in the core, and "smallcore", which treats the four, five and six shell electrons explicitly. The use of large-core RECPs (LCRECP) has been justified by the fact that $4 \mathrm{f}$ orbitals do not significantly contribute to bonding due to their limited radial extension as compared to the $5 \mathrm{~d}$ and $6 \mathrm{~s}$ shells. The use of LCRECPs requires a separate potential for each oxidation state or $4 \mathrm{f}$ subconfiguration, and thus in practice eliminates most of the magnetic and electronic subtleties of the lanthanides, thereby precluding the modeling of $\mathrm{f}-\mathrm{f}$ centered processes and the treatment of spin-orbit coupling. However, this approach avoids many difficulties associated to the computational treatment of open-shell systems, and despite its approximate nature is an efficient computational tool that has proven to give good results in studies that focus on the structural features or the estimates of relative energies for $\mathrm{Ln}^{\mathrm{III}}$ complexes at both the HF and DFT level ${ }^{[33]}$. 
The aim of this work is to benchmark different functionals to find those that best reproduce the molecular geometries in aqueous solution of $\mathrm{Ln}^{\mathrm{III}}$ complexes relevant to the molecular imaging field. The relatively large size of these systems often prevents their investigation at a reasonable computational cost using smallcore RECPs and extended basis-sets for the ligand atoms. Thus, in this work we used the LCRECP of Dolg et al. and the related [5s4p3d]-GTO valence basis set for $\mathrm{Eu}, \mathrm{Gd}$ and $\mathrm{Tb}^{[73]}$, while in most calculations the 6$31 \mathrm{G}(\mathrm{d})$ basis set was used for $\mathrm{C}, \mathrm{H}, \mathrm{N}, \mathrm{O}, \mathrm{F}$ and $\mathrm{P}$ atoms. This basis set may be considered the largest practical polarized double- $\zeta$ basis set that can be used in geometry optimizations of the model systems presented in this work at the MP2 level. Test calculations on Gd model systems were also performed by using the SCRECP approach. In the latter cases we considered the highest spin state as the ground state (octuplet, $4 \mathrm{f}^{7}$ ). Since geometry optimizations were performed by using an unrestricted model, spin contamination was assessed by a comparison of the expected difference between $S(S+1)$ for the assigned spin state and the actual value of $\left\langle S^{2}\right\rangle^{[78,79]}$. The results indicate that spin contamination is negligible for all complexes. Basis set effects on molecular geometries were evaluated by performing optimizations using different basis sets for the ligand atoms (STO-3G, 3-21G, 6-31G, 6-311G, 6-311G(d), 6-311G(d,p), 6$311+\mathrm{G}(\mathrm{d}, \mathrm{p})$, cc-pVDZ and cc-pVTZ) in combination with the LCRECP for the lanthanide and the mPWB95 functional. Those basis sets that do not contain polarization functions (STO-3G, 3-21G, 6-31G, 6-311G) were not used to investigate the model systems containing $\mathrm{P}$ atoms.

The Dunning basis sets constitute hierarchical sequences that allow the extrapolation of the calculated energy to the complete basis-set (CBS) limit. Thus, we have performed single-point energy calculations for selected systems using cc-pVxZ ( $x=\mathrm{D}, \mathrm{T}, \mathrm{Q}, 5$, in some cases 6) and aug-cc-pVxZ ( $x=\mathrm{D}, \mathrm{T}$, in some cases $\mathrm{Q})$. Extrapolation to the CBS limit was then achieved by fitting the calculated results to the following threeparameter function ${ }^{[80]}$ :

$$
Y(\mathrm{x})=Y(\infty)+A \exp (-\mathrm{x} / B)
$$

where the extrapolated value $Y(\infty)$ corresponds to the best estimate of the predicted energy for infinite zeta and $A$ and $B$ are fitted parameters. The energy of selected systems was also extrapolated to the MP2/CBS limit employing Truhlar extrapolation scheme and aug-cc-pVxZ $(x=\mathrm{D}$ and $\mathrm{T})$ basis sets according to the following equation ${ }^{[81]}$ :

$E_{\mathrm{MP} 2 / \mathrm{CBS}}^{\text {Truhlar }}=\frac{3^{\alpha}}{3^{\alpha}-2^{\alpha}} E_{\mathrm{HF} / \mathrm{TZ}}-\frac{2^{\alpha}}{3^{\alpha}-2^{\alpha}} E_{\mathrm{HF} / \mathrm{DZ}}+\frac{3^{\beta}}{3^{\beta}-2^{\beta}} E_{\mathrm{corr} / \mathrm{TZ}}-\frac{2^{\beta}}{3^{\beta}-2^{\beta}} E_{\mathrm{corr} / \mathrm{DZ}}$

In Eq. (2) the parameters $\alpha$ and $\beta$ have the values of 4.93 and $2.13^{[82]}$, and $E_{\text {corr/DZ }}$ energies and $E_{\text {corr/TZ were }}$ obtained with MP2/aug-cc-pVDZ and MP2/aug-cc-pVTZ calculations, respectively.

In the absence of reliable experimental data, high-level correlated wave-function based ab initio computational methods constitute the only practical reference data for creating benchmarks against which the performance of various methods and basis sets can be evaluated ${ }^{[83]}$. However, the relatively large size of the systems investigated here and the scaling behavior of these methods with system size prevent their application with our currently available computational resources. Thus, the geometries obtained from HF and DFT calculations were compared to those obtained from MP2/LCRECP/6-31G(d) calculations as benchmark. To test whether an accurate set of benchmark geometries can be computed using 
MP2/LCRECP/6-31G(d) as the basis, we first established the quality of the structures obtained by this method for four small systems $\left[\mathrm{GdH}_{2} \mathrm{O}^{3+}, \mathrm{GdNH}_{3}{ }^{3+}, \mathrm{GdF}^{2+}\right.$ and $\left.\mathrm{GdO}^{+}\right]$against QCISD/LCRECP/6-311G(d,p) optimized geometries $^{[84]}$. The differences between the Gd-donor distances obtained from MP2/LCRECP/631G(d) and QCISD/LCRECP/6-311G(d,p) calculations among these four molecules fall within the range 0.011-0.027 $\AA$, the larger deviation being observed for $\mathrm{GdF}^{2+}$. Therefore, we conclude that MP2/LCRECP/6$31 \mathrm{G}(\mathrm{d})$ geometries can be used as the standard against which DFT geometries can be evaluated.

Solvent effects were evaluated by using the polarizable continuum model (PCM), in which the solute cavity is built as an envelope of spheres centered on atoms or atomic groups with appropriate radii. In particular, we used the integral equation formalism (IEFPCM) variant as implemented in Gaussian $09^{[85]}$.

Full geometry optimizations of different $\mathrm{Ln}^{\mathrm{III}}$ complexes whose X-ray diffraction structures were published, were performed by using the combination of basis sets LCRECP/6-31G(d) and the G96LYP, B3LYP, mPWB95 and TPSSh functionals. Geometry optimizations in aqueous solution for these systems were performed at the mPWB95/LCRECP/6-31G(d) level. The X-ray crystal structures were used as input geometries, and the stationary points found on the potential energy surfaces as a result of the geometry optimizations were characterized by frequency analysis.

\section{Results and discussion}

\subsection{Calculations on model systems: geometric dependence upon density functionals}

In order to assess the applicability of different density functionals to predict the geometries of $\mathrm{Ln}^{\mathrm{III}}$ complexes relevant in the molecular imaging field, we investigated the structures of different model systems using LSDA, GGA, hybrid-, meta-GGA and hybrid meta-GGA functionals with the LCRECP for the lanthanides $(\mathrm{Eu}, \mathrm{Gd}$ or $\mathrm{Tb})$ and the standard 6-31G(d) basis set for ligand atoms. Furthermore, we have also tested the CAM-B3LYP and wB97XD functionals, which include long range corrections. The model systems were chosen to cover those binding motifs more often present in ligands designed for stable $\mathrm{Ln}^{\text {III }}$ complexation in aqueous solution (Fig. 1). These binding motifs include pyridine (py), pyridine-2carboxylate (py2COO) and 2,2'-bipyridine (bipy) units present in many ligands used to design $\mathrm{Eu}^{\mathrm{III}}$ and $\mathrm{Tb}^{\mathrm{III}}$ luminescent complexes, 1,2-dimethoxyethane (dme), $N^{1}, N^{1}, N^{2}, N^{2}$-tetramethylethane-1,2-diamine (tmda) and 2-methoxy- $N, N$-dimethylethanamine (mdmea) units found in ligands based on aza- and oxaaza macrocycles and polyaminocarboxylates, and 2-(dimethylamino)acetate (dmaac), ((dimethylamino)methyl)phosphonate (dmaphos) and 2-(dimethylamino)- $N, N$-dimethylacetamide (dmadmam) moieties present in many cyclen-based ligands. Additionally, different model systems containing biologically important anionssuch as lactate (lac), carbonate or phosphate were considered. Finally, a model system containing a fluoride anion, which is known to bind rather strongly to the trivalent lanthanides, was also investigated ${ }^{[86]}$. The $\mathrm{Ln}^{\text {III }}$ ions in aqueous solution show a preference for high coordination numbers (typically $8-9)^{[15]}$. In the particular case of the $\mathrm{Ln}^{\mathrm{III}}$ aqua-ions it is generally accepted that the number of inner-sphere water molecules in the first coordination sphere of the $\mathrm{Ln}^{\mathrm{III}}$ aquaions amounts to 9 for the largest $\mathrm{Ln}^{\mathrm{III}}$ ions and then decreases to 8 as the ionic radius of the metal ion decreases ${ }^{[87,88]}$. Thus, in our calculations water molecules were added to our model systems to satisfy a coordination number of eight. For comparative purposes calculations at the HF level were also performed.

Geometry optimizations at the MP2 (Fig. 1), HF and DFT levels lead to eight-coordinate species for all model systems, except in the case of $\left[\operatorname{Ln}(\mathrm{dmaphos})\left(\mathrm{H}_{2} \mathrm{O}\right)_{2}\right]^{+}(\mathbf{8})$, for which one water molecule is expulsed from the first coordination sphere of the metal ion during the optimization process. This is most likely due to the steric hindrance that the relatively bulky dmaphos ${ }^{2-}$ unit causes around the metal ion. As expected, the optimized geometries of the $\left[\mathrm{Ln}\left(\mathrm{H}_{2} \mathrm{O}\right)_{8}\right]^{3+}$ systems present a square-antiprismatic coordination environment around the metal ion ${ }^{[88,89]}$. The bond angles around the metal ion calculated at the HF and DFT levels show a 
good agreement with those obtained with MP2 calculations, with deviations typically $<2^{\circ}$. However, important differences on the bond distances of the metal coordination environment are observed depending on the particular model used. The agreement between the bond distances obtained at HF and DFT levels with those obtained by using MP2 theory was assessed by using the unsigned mean error (UME), as given by following equation:

$\mathrm{UME}=\frac{1}{n} \sum_{i=1}^{n}\left|D_{\mathrm{MP} 2}-D_{\mathrm{DFT}}\right|$

where $D_{\mathrm{MP} 2}$ and $D_{\mathrm{DFT}}$ are the bond distances calculated at the MP2 and DFT levels, respectively. The average UME values obtained from geometry optimizations of the $15 \mathrm{Eu}^{\mathrm{III}}$ model systems investigated in this work are shown in Fig. 2. Similar average UME values were obtained in the case of the $\mathrm{Gd}^{\mathrm{III}}$ and $\mathrm{Tb}^{\mathrm{III}}$ analogues (Table 1, Figs. S1 and S2).

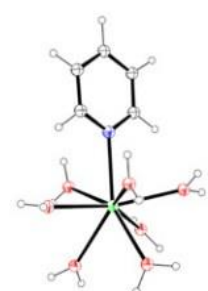

$\left[\mathrm{Eu}(\mathrm{py})\left(\mathrm{H}_{2} \mathrm{O}\right)_{7}\right]^{3+}(1)$

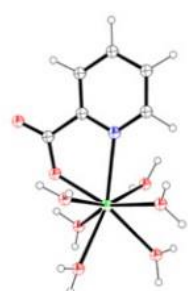

$\left[\mathrm{Eu}(\mathrm{py} 2 \mathrm{COO})\left(\mathrm{H}_{2} \mathrm{O}\right)_{6}\right]^{2+}(2)$

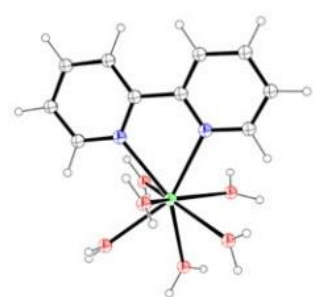

$\left[\mathrm{Eu}(\mathrm{bipy})\left(\mathrm{H}_{2} \mathrm{O}\right)_{6}\right]^{3+}(3)$

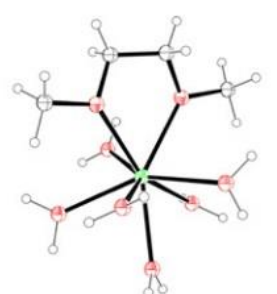

$\left[\mathrm{Eu}(\mathrm{dme})\left(\mathrm{H}_{2} \mathrm{O}\right)_{6}\right]^{3+}(4)$

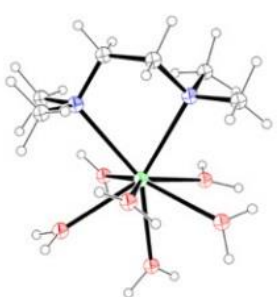

$\left[\mathrm{Eu}(\mathrm{tmea})\left(\mathrm{H}_{2} \mathrm{O}\right)_{6}\right]^{3+}(\mathbf{5})$

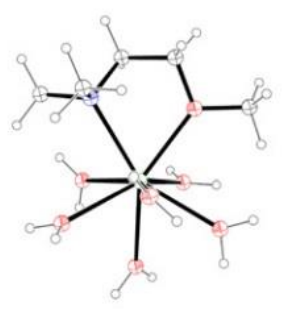

$\left[\mathrm{Eu}(\mathrm{mdmea})\left(\mathrm{H}_{2} \mathrm{O}\right)_{6}\right]^{3+}(6)$

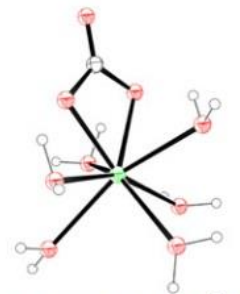

$\left[\mathrm{Eu}\left(\mathrm{CO}_{3}\right)\left(\mathrm{H}_{2} \mathrm{O}\right)_{6}\right]^{+}(11)$

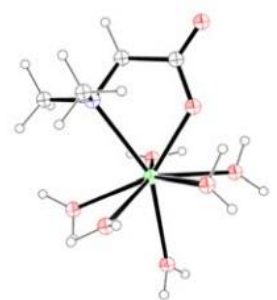

$\left[\mathrm{Eu}(\mathrm{dmaac})\left(\mathrm{H}_{2} \mathrm{O}\right)_{6}\right]^{2+}(7)$

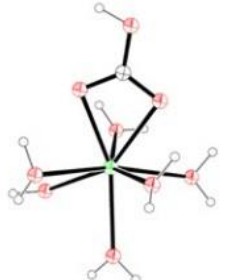

$\left[\mathrm{Eu}\left(\mathrm{HCO}_{3}\right)\left(\mathrm{H}_{2} \mathrm{O}\right)_{6}\right]^{2+}(\mathbf{1 2})$

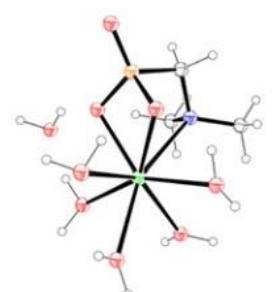

$\left[\mathrm{Eu}(\mathrm{dmaphos})\left(\mathrm{H}_{2} \mathrm{O}\right)_{6}\right]^{+}(\mathbf{8})$

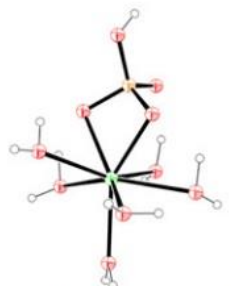

$\left[\mathrm{Eu}\left(\mathrm{HPO}_{3}\right)\left(\mathrm{H}_{2} \mathrm{O}\right)_{6}\right]^{+}(13)$
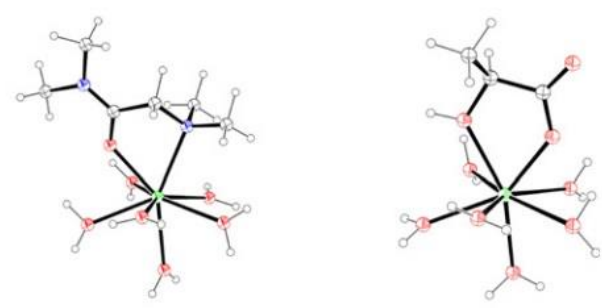

$\left[\mathrm{Eu}(\mathrm{dmadmam})\left(\mathrm{H}_{2} \mathrm{O}\right)_{6}\right]^{3+}(\mathbf{9}) \quad\left[\mathrm{Eu}(\mathrm{lac})\left(\mathrm{H}_{2} \mathrm{O}\right)_{6}\right]^{2+}(\mathbf{1 0})$
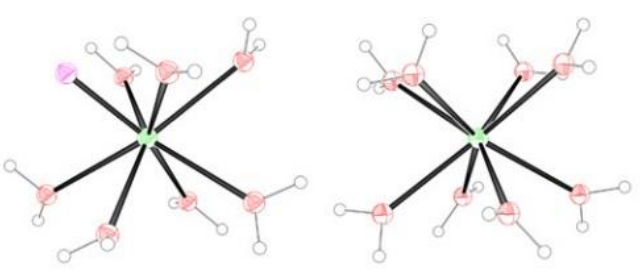

$\left[\mathrm{Eu}(\mathrm{F})\left(\mathrm{H}_{2} \mathrm{O}\right)_{7}\right]^{2+}(\mathbf{1 4})$

$\left[\mathrm{Eu}\left(\mathrm{H}_{2} \mathrm{O}\right)_{8}\right]^{3+}(15)$

Fig. 1. Geometries of the Eu ${ }^{\mathrm{III}}$ model systems investigated in this work optimized at the MP2/LCRECP/6-31G(d) level. Optimized Cartesian coordinates are given in the Supporting information.

The UME values shown in Fig. 2 indicate that LSDA functionals (SVWN and SPL) provide the poorest agreement with the distances obtained from MP2 calculations, with mean deviations above $0.06 \AA$. Furthermore, both the $\mathrm{Eu}-\mathrm{N}$ and $\mathrm{Eu}-\mathrm{O}$ distances show very similar UME values. An important improvement in the agreement between DFT and MP2 bond distances is observed when using GGA functionals (BLYP, 
G96LYP or mPWLYP), which provide similar agreements than HF calculations. However, a closer inspection of the bond distances shows that this improvement affects mainly to the Ln-O distances, while the deviations observed for Ln-N distances are still large ( $>0.04 \AA$ ). Among the three GGA functionals explored BLYP appears to perform slightly better than mPWLYP and G96LYP. The use of hybrid-GGA functionals further improves the agreement with MP2 calculations, particularly in the case of BH\&HLYP and B3PW91, which provide considerably lower UME values than the popular B3LYP. Even so, all hybrid-GGA functionals provide $\mathrm{Ln}-\mathrm{N}$ distances considerably longer than MP2 calculations. The best agreement between DFT optimized geometries and those obtained from MP2 calculations is provided by meta-GGA and hybrid meta-GGA functionals. Taking the data for $\mathrm{Eu}^{\mathrm{III}}, \mathrm{Gd}^{\mathrm{III}}$ and $\mathrm{Tb}^{\mathrm{III}}$ as a whole we conclude that all meta-GGA and hybrid meta-GGA functionals tested (mPWB95, BB95, TPSS, TPSSh and M06) provide results of similar quality, with mean deviations below $0.02 \AA$ for $\mathrm{Eu}^{\mathrm{III}}$ and $\mathrm{Tb}^{\mathrm{III}}$ complexes, and below $0.03 \AA$ for $\mathrm{Gd}^{\mathrm{III}}$ systems. The use of long range-corrected functionals (CAM-B3LYP and wB97XD) does not result in a better agreement with MP2 calculations in comparison to meta-GGA and hybrid meta-GGA functionals.

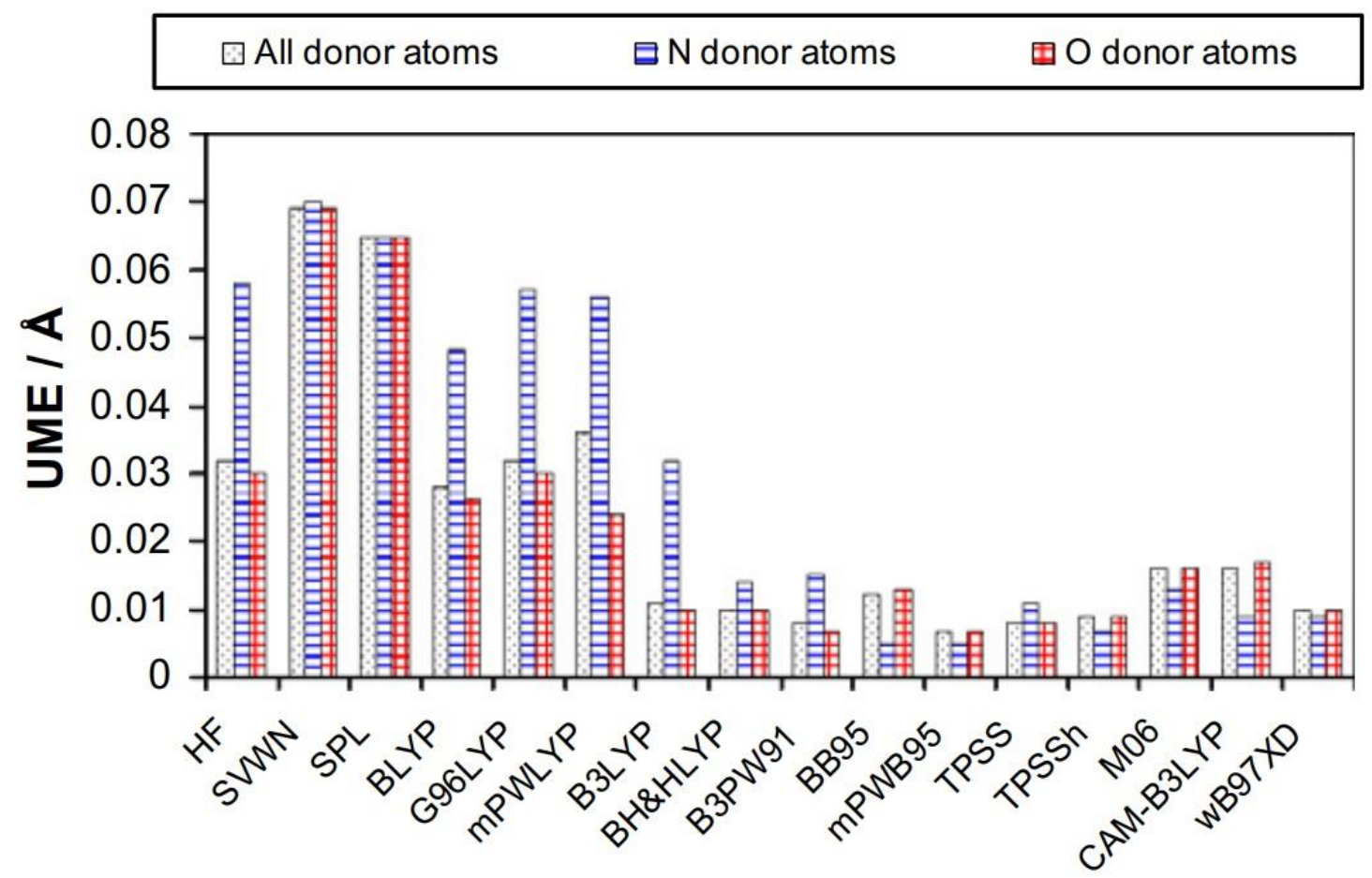

Fig. 2. Unsigned mean error (UME) values $(\AA)$ obtained for the Eu ${ }^{\mathrm{III}}$ model systems $\mathbf{1}-\mathbf{1 5}$ compared to those obtained from MP2/LCRECP/6-31G(d) calculations as benchmark.

The bond distances calculated with different functionals for the representative $\left[\mathrm{Eu}(\mathrm{tmea})\left(\mathrm{H}_{2} \mathrm{O}\right)_{6}\right]^{3+}$ and $\left[\mathrm{Eu}(\mathrm{dmadman})\left(\mathrm{H}_{2} \mathrm{O}\right)_{6}\right]^{3+}$ systems are compared to those obtained from MP2 calculations in Fig. 3. The trend followed by the bond distances is reproduced reasonably well by all functionals explored. However, use of LSDA functionals provides very short bond distances, in line with previous studies that showed that these functionals often predict overbinding ${ }^{[35,42]}$. On the contrary, GGA functionals such as G96LYP provide significantly longer distances than MP2, a situation also observed for $\mathrm{Ln}-\mathrm{N}$ bonds with the use of hybridGGA functionals. 
Table 1. Calculated unsigned mean error values (UME, $\AA$ ) in $\mathrm{Ln}^{\mathrm{III}}-$ donor bond lengths of systems $\mathbf{1}-\mathbf{1 5}$.

\begin{tabular}{|c|c|c|c|c|c|}
\hline Type & Functional & & $\mathrm{Eu}^{\mathrm{III}}$ & $\mathrm{Gd}^{\mathrm{III}}$ & $\mathrm{Tb}^{\mathrm{III}}$ \\
\hline \multirow[t]{6}{*}{$\overline{\mathrm{LSDA}}$} & SVWN & $\mathrm{Ln}-\mathrm{N}$ & 0.070 & 0.049 & 0.057 \\
\hline & & $\mathrm{Ln}-\mathrm{O}$ & 0.069 & 0.063 & 0.070 \\
\hline & & Total & 0.069 & 0.062 & 0.070 \\
\hline & SPL & Ln-N & 0.065 & 0.041 & 0.061 \\
\hline & & $\mathrm{Ln}-\mathrm{O}$ & 0.065 & 0.060 & 0.066 \\
\hline & & Total & 0.065 & 0.058 & 0.066 \\
\hline \multirow[t]{9}{*}{ GGA } & BLYP & Ln-N & 0.048 & 0.069 & 0.049 \\
\hline & & $\mathrm{Ln}-\mathrm{O}$ & 0.026 & 0.040 & 0.029 \\
\hline & & Total & 0.028 & 0.040 & 0.030 \\
\hline & G96LYP & Ln-N & 0.057 & 0.079 & 0.057 \\
\hline & & $\mathrm{Ln}-\mathrm{O}$ & 0.030 & 0.041 & 0.032 \\
\hline & & Total & 0.032 & 0.043 & 0.034 \\
\hline & mPWLYP & $\mathrm{Ln}-\mathrm{N}$ & 0.056 & 0.062 & 0.039 \\
\hline & & $\mathrm{Ln}-\mathrm{O}$ & 0.024 & 0.031 & 0.022 \\
\hline & & Total & 0.026 & 0.033 & 0.024 \\
\hline \multirow[t]{9}{*}{ Hybrid-GGA } & B3LYP & $\mathrm{Ln}-\mathrm{N}$ & 0.032 & 0.050 & 0.028 \\
\hline & & $\mathrm{Ln}-\mathrm{O}$ & 0.010 & 0.019 & 0.013 \\
\hline & & Total & 0.011 & 0.022 & 0.014 \\
\hline & BH\&HLYP & Ln-N & 0.014 & 0.032 & 0.015 \\
\hline & & $\mathrm{Ln}-\mathrm{O}$ & 0.010 & 0.006 & 0.012 \\
\hline & & Total & 0.010 & 0.008 & 0.013 \\
\hline & B3PW91 & $\mathrm{Ln}-\mathrm{N}$ & 0.015 & 0.034 & 0.016 \\
\hline & & $\mathrm{Ln}-\mathrm{O}$ & 0.007 & 0.013 & 0.011 \\
\hline & & Total & 0.008 & 0.014 & 0.011 \\
\hline \multirow[t]{12}{*}{ Meta-GGA } & BB95 & Ln-N & 0.005 & 0.026 & 0.005 \\
\hline & & $\mathrm{Ln}-\mathrm{O}$ & 0.013 & 0.025 & 0.015 \\
\hline & & Total & 0.012 & 0.025 & 0.015 \\
\hline & mPWB95 & Ln-N & 0.005 & 0.019 & 0.013 \\
\hline & & $\mathrm{Ln}-\mathrm{O}$ & 0.007 & 0.019 & 0.017 \\
\hline & & Total & 0.007 & 0.019 & 0.015 \\
\hline & TPSS & $\mathrm{Ln}-\mathrm{N}$ & 0.011 & 0.030 & 0.011 \\
\hline & & $\mathrm{Ln}-\mathrm{O}$ & 0.008 & 0.013 & 0.013 \\
\hline & & Total & 0.008 & 0.014 & 0.013 \\
\hline & M06 & $\mathrm{Ln}-\mathrm{N}$ & 0.013 & 0.012 & 0.015 \\
\hline & & $\mathrm{Ln}-\mathrm{O}$ & 0.016 & 0.015 & 0.021 \\
\hline & & Total & 0.016 & 0.015 & 0.021 \\
\hline \multirow[t]{3}{*}{ Hybrid meta-GGA } & TPSSh & $\mathrm{Ln}-\mathrm{N}$ & 0.007 & 0.025 & 0.008 \\
\hline & & $\mathrm{Ln}-\mathrm{O}$ & 0.009 & 0.009 & 0.015 \\
\hline & & Total & 0.009 & 0.011 & 0.014 \\
\hline \multirow[t]{6}{*}{ Long-range corrected } & CAM-B3LYP & $\mathrm{Ln}-\mathrm{N}$ & 0.009 & 0.029 & 0.009 \\
\hline & & $\mathrm{Ln}-\mathrm{O}$ & 0.017 & 0.013 & 0.018 \\
\hline & & Total & 0.016 & 0.015 & 0.018 \\
\hline & wB97XD & $\mathrm{Ln}-\mathrm{N}$ & 0.009 & 0.016 & 0.008 \\
\hline & & $\mathrm{Ln}-\mathrm{O}$ & 0.010 & 0.018 & 0.013 \\
\hline & & Total & 0.010 & 0.014 & 0.013 \\
\hline
\end{tabular}




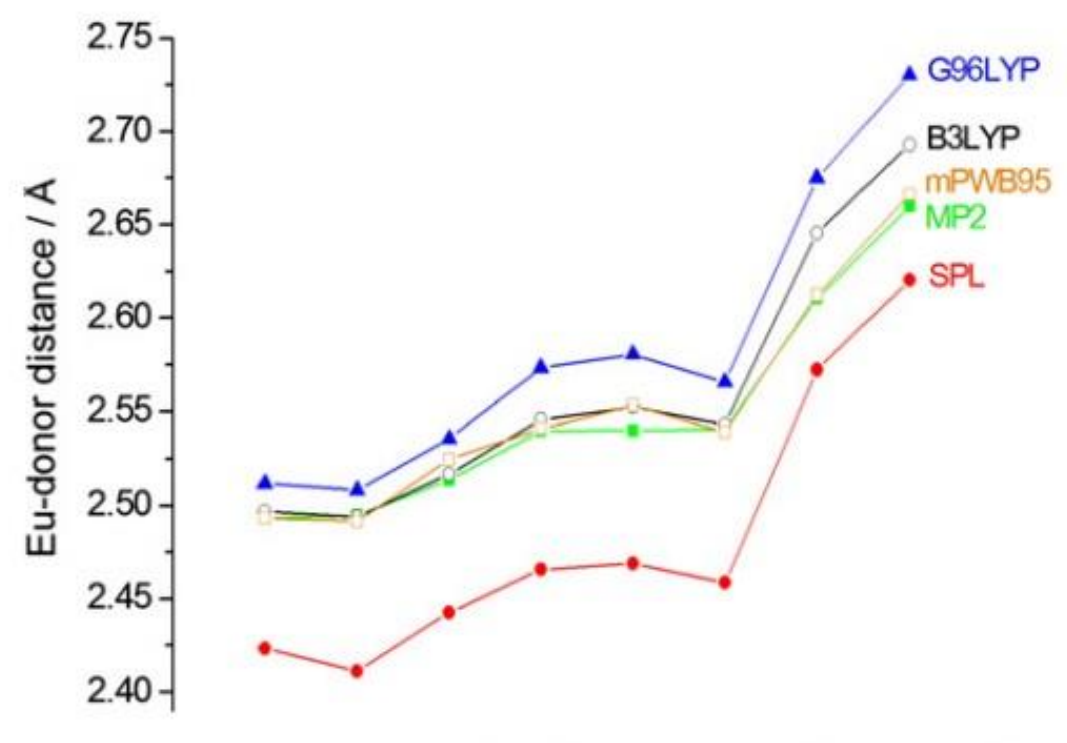

oxygen donor atoms__ nitrogen donor atoms

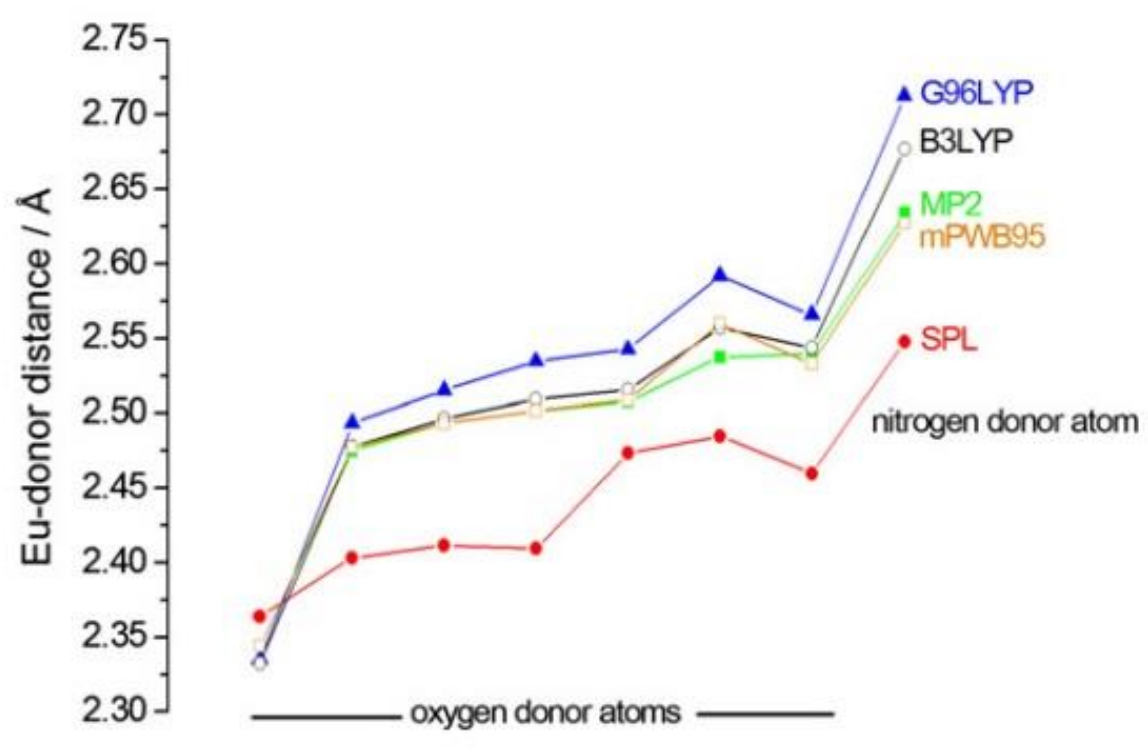

Fig. 3. Eu-donor atom distances calculated with different functionals compared to those obtained with full MP2/LCRECP/6-31G(d) calculations for $\left[\mathrm{Eu}(\mathrm{tmea})\left(\mathrm{H}_{2} \mathrm{O}\right)_{6}\right]^{3+}(\mathbf{5}$, top $)$ and $\left[\mathrm{Eu}(\mathrm{dmadman})\left(\mathrm{H}_{2} \mathrm{O}\right)_{6}\right]^{3+}(\boldsymbol{9}$, bottom).

To understand the reasons behind the larger deviations of the Ln-N distances calculated with GGA and hybrid GGA functionals in comparison to the Ln-O distances, we have performed potential-energy surface scans of the model system 7 at the B3LYP/LCRECP/6-31G(d) level (Fig. 4). The results show that the potential energy surface generated by changing the $\mathrm{Eu}-\mathrm{N}$ distance is rather shallow, while the potential surface obtained by varying the Eu-O distance is considerably steeper. This can be interpreted in terms of the stronger binding provided by oxygen donor atoms, particularly when they are negatively charged, and complicates the problem of a precise theoretical determination of the $\mathrm{Ln}-\mathrm{N}$ distances ${ }^{[90]}$. A similar situation is observed at the mPWB95/LCRECP/6-31G(d) level, although the energy minimum for the variation of the $\mathrm{Ln}-\mathrm{N}$ distance is considerably shifted with respect to that obtained from B3LYP calculations. The poor performance of B3LYP compared to BH\&HLYP and B3PW91 to reproduce the Ln-N distances obtained from MP2 calculations is in line with previous investigations that found serious failures of the B3LYP functional that may arise from design problems ${ }^{[91]}$. For instance, it has been shown that B3LYP fails to provide accurate geometries of iron porphyrins and organolithium carbenoids ${ }^{[92,83]}$. 


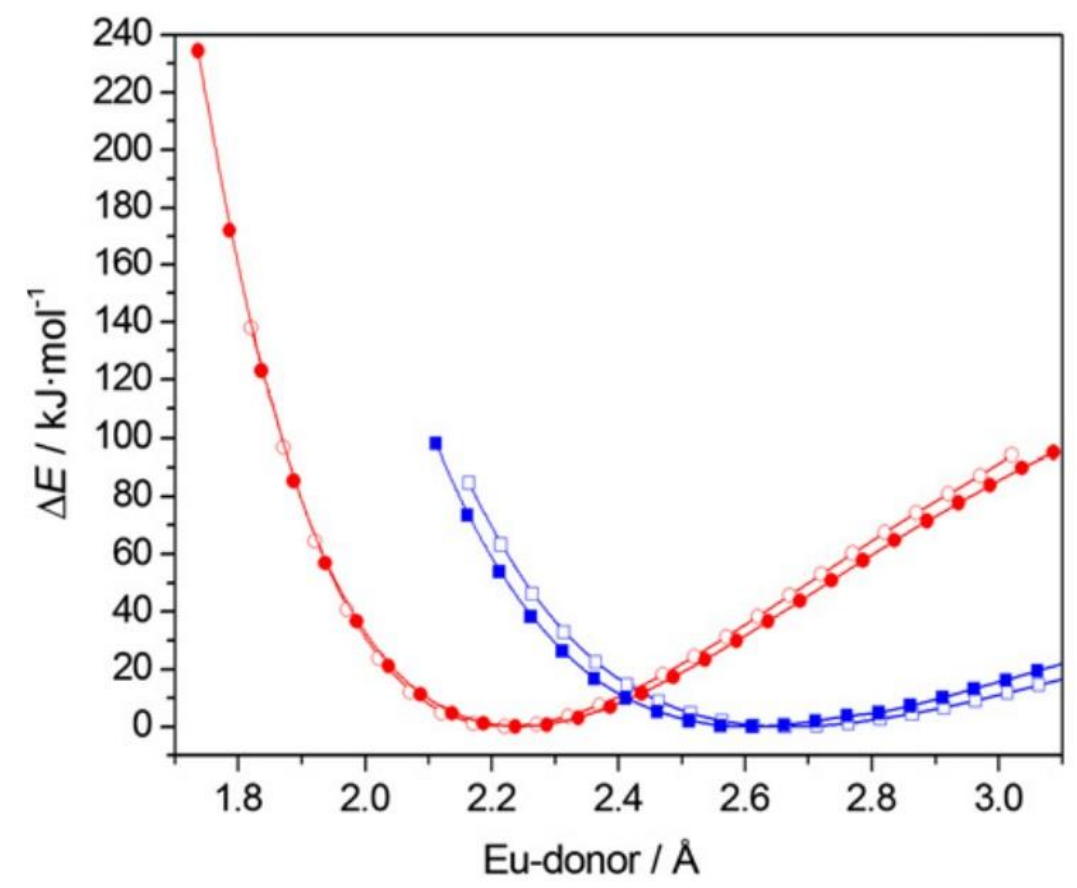

Fig. 4. Relaxed potential energy surfaces generated for 7 upon changing the Eu- $\mathrm{O}_{\text {carboxylate }}$ (circles) and Eu-N distances (squares) at the B3LYP/LCRECP/6-31G(d) (open symbols) and mPWB95/LCRECP/6-31G(d) (filled symbols) levels.

\subsection{Geometry dependence upon basis set and efficiency considerations}

The effect of the basis set size used for describing the ligand atoms was examined by performing geometry optimizations on the 15 model systems shown in Fig. 1 with the meta-GGA mPWB95 functional. The main results are shown in Fig. 5, which shows the UME values obtained by using mPWB95/LCRECP/6$311+\mathrm{G}(\mathrm{d}, \mathrm{p})$ calculations as standard. Our results show that both polarized double- $\zeta(6-31 \mathrm{G}(\mathrm{d})$ and cc-pVDZ) and polarized triple- $\zeta(6-311 \mathrm{G}(\mathrm{d}), 6-311 \mathrm{G}(\mathrm{d}, \mathrm{p})$ and cc-pVTZ) basis sets provide very similar bond distances of the metal coordination environment, the largest deviation from mPWB95/LCRECP/6-311+G(d,p) calculations amounting to $0.022 \AA$. The Eu-donor distances calculated with non-polarized basis sets (3-21G, 6-31G, 6-311G) are noticeably shorter than those obtained with polarized ones, and this effect is strongly enhanced with the STO-3G basis set. A similar trend was previously observed with HF calculations on the $\left[\mathrm{Gd}\left(\mathrm{H}_{2} \mathrm{O}\right)_{9}\right]^{3+}$ system $^{[93]}$. This was attributed to the use of unbalanced basis sets, as the basis set used for the metal is of much better quality with respect to the STO-3G basis set, thereby inducing the ligands donor atoms to use the basis functions of the metal. In line with these results, Simas et al. observed that HF/LCRECP/STO-3G calculations provide molecular geometries for $\mathrm{Ln}^{\mathrm{III}}$ complexes in better agreement with experimental X-ray structures than analogous calculations using larger basis sets ${ }^{[94]}$. Considering the results presented in the previous section, this can be attributed to the cancellation of two opposite effects: the use of unbalanced basis sets (LCRECP/STO-3G), which results in a shortening of the Ln-donor distances, and the trend of HF calculations to overestimate the Ln-donor distances, particularly when nitrogen donor atoms are present.

Different computational studies have shown that $4 \mathrm{f}$-in-core calculations provide longer metal-donor distances than SCRECP calculations ${ }^{[95,96]}$. Thus, we performed geometry optimizations of the $15 \mathrm{Gd}^{\mathrm{III}}$ model systems presented in this work at the mPWB95/SCRECP/6-31G(d) level. Geometry optimizations performed on systems 13 and 15 with the SCRECP did not achieve convergence. Thus, the LCRECP bond distances of the metal coordination environment obtained for the remaining 13 model systems are compared to those obtained with SCRECP calculations in Fig. 6 and Table 2. Our calculations indeed show that SCRECP calculations provide somewhat shorter $\mathrm{Gd}^{\mathrm{III}}$-donor distances than the LCRECP approach. However, the 
shortening of bond lengths is relatively small, the average contraction of bond distances amounting to $0.033 \AA$ for the 13 systems investigated. This effect is somewhat larger for the $\mathrm{Gd}-\mathrm{N}$ distances than for the Gd-O distances, which shorten on average 0.042 and $0.028 \AA$, respectively. Thus, we conclude that the impact of using LCRECPs instead of SC ones in the geometries of these family of complexes is relatively small compared to other factors such as the DFT functional used.

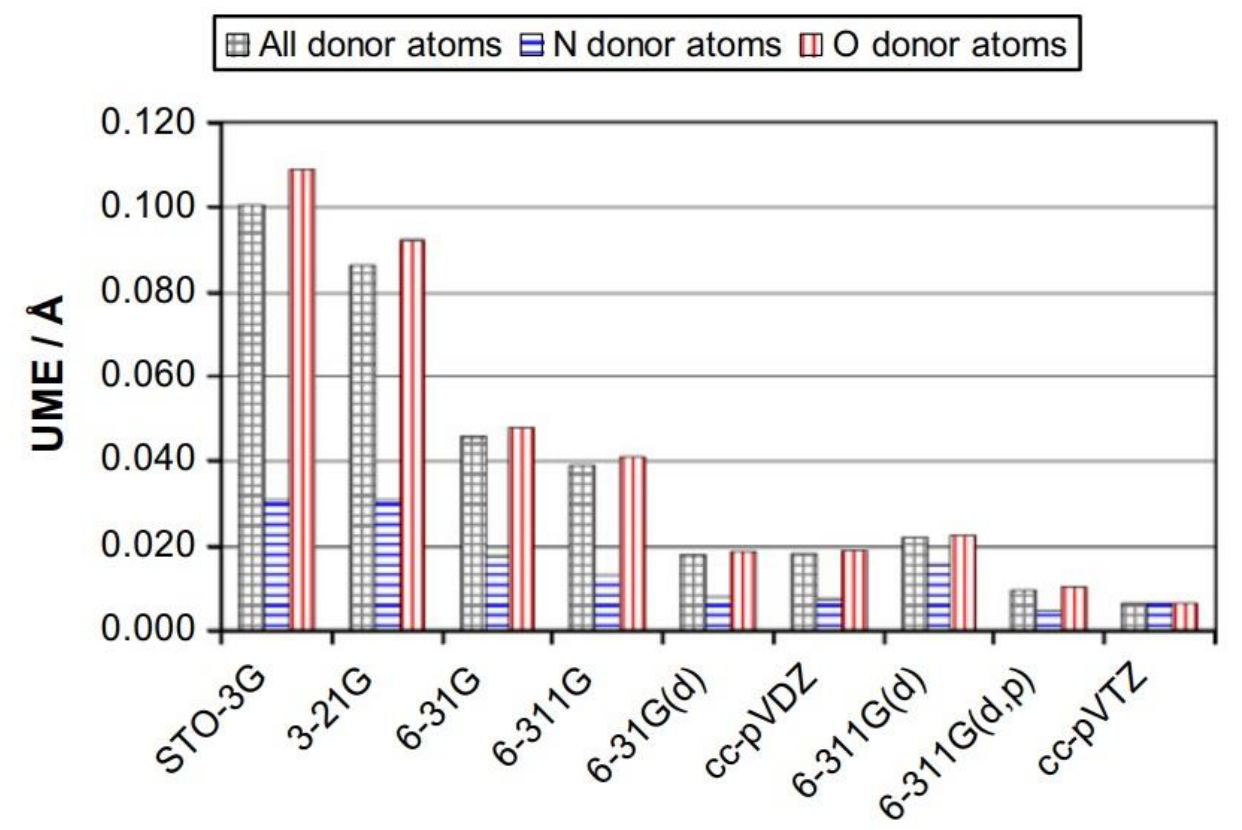

Fig. 5. Unsigned mean error (UME) values $(\AA)$ obtained for the Eu ${ }^{\text {III }}$ model systems investigated in this work by using different basis sets (mPWB95/LCRECP) compared to those obtained from $\mathrm{mPWB} 95 / \mathrm{LCRECP} / 6-311+\mathrm{G}(\mathrm{d}, \mathrm{p})$ calculations as benchmark.

Table 2. Mean Gd-N and Gd-O bond distances ( $\AA$ ) obtained with the use of mPWB95/SCRECP/6-31G(d) and mPWB95/LCRECP/6-31G(d) calculations.

\begin{tabular}{cllll}
\hline System & Gd-N $(\mathrm{LC})$ & $\mathrm{Gd}-\mathrm{N}(\mathrm{SC})$ & $\mathrm{Gd}-\mathrm{O}(\mathrm{LC})$ & $\mathrm{Gd}-\mathrm{O}(\mathrm{SC})$ \\
\hline $\mathbf{1}$ & 2.521 & 2.479 & 2.488 & 2.452 \\
$\mathbf{2}$ & 2.542 & 2.512 & 2.474 & 2.451 \\
$\mathbf{3}$ & 2.502 & 2.465 & 2.504 & 2.470 \\
$\mathbf{4}$ & - & - & 2.478 & 2.442 \\
$\mathbf{5}$ & 2.628 & 2.585 & 2.511 & 2.483 \\
$\mathbf{6}$ & 2.605 & 2.568 & 2.497 & 2.465 \\
$\mathbf{7}$ & 2.602 & 2.566 & 2.474 & 2.452 \\
$\mathbf{8}$ & 2.676 & 2.609 & 2.454 & 2.433 \\
$\mathbf{9}$ & 2.616 & 2.569 & 2.476 & 2.446 \\
$\mathbf{1 0}$ & - & - & 2.461 & 2.432 \\
$\mathbf{1 1}$ & - & - & 2.460 & 2.439 \\
$\mathbf{1 2}$ & - & - & 2.454 & 2.425 \\
$\mathbf{1 4}$ & - & - & 2.508 & 2.485 \\
\hline
\end{tabular}




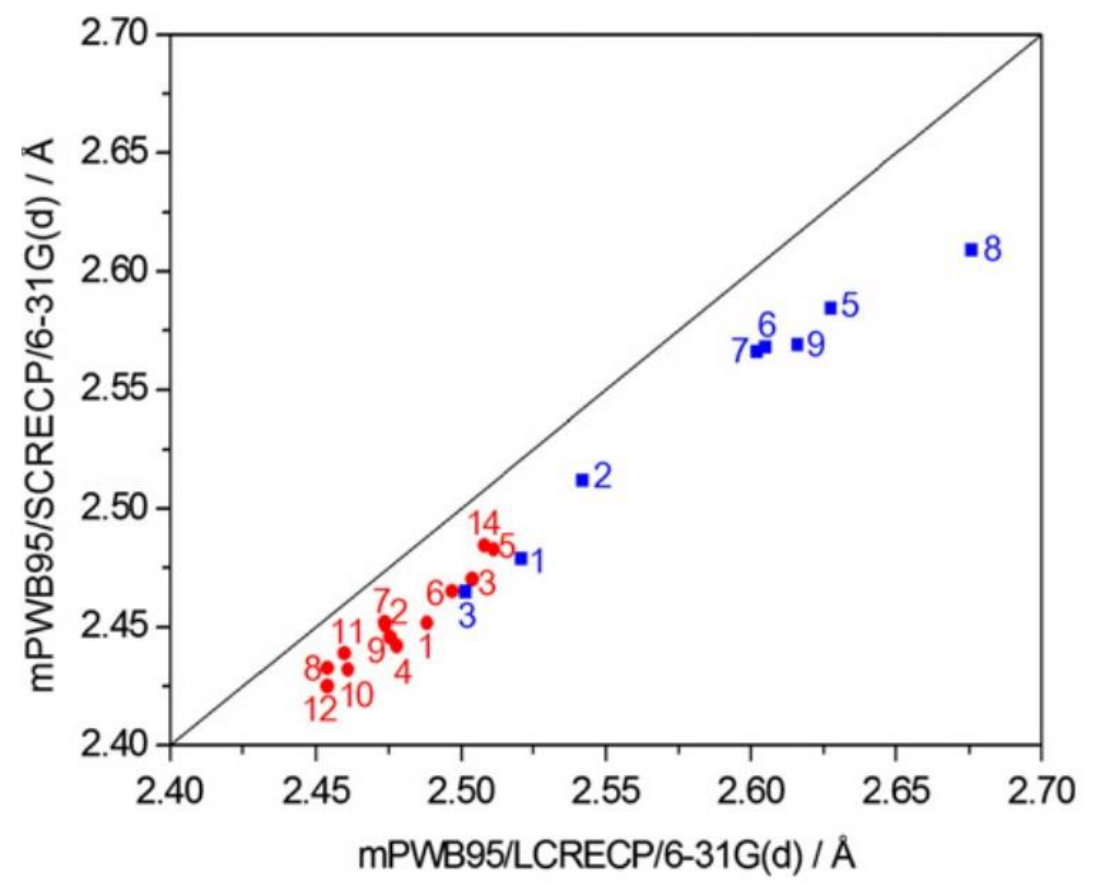

Fig. 6. Comparison of Gd-donor distances $(\AA)$ obtained with LCRECP and SCRECP calculations and the mPWB95 functional. The solid line represents a 1:1 relationship between the two sets of data. Data below the line indicate that SCRECP distances are shorter than LCRECP ones. Squares: Gd-N distances; Circles: Gd-O distances.

An estimation of the computational time required in the geometry optimization process for different density functionals and basis sets depends on different aspects such as (i) the number of basis functions used; (ii) the time required by a SCF cycle and the number of cycles required for convergence, (iii) the number of intermediate geometries required for the optimization to be completed ${ }^{[97]}$. In the particular case of the lanthanide ions the inclusion of $4 \mathrm{f}$ electrons in the valence space obviously increases the computational cost and introduces some difficulties associated to the computational treatment of open-shell systems. Thus, we have estimated the time required in a geometry optimization process as a function of the density functional used, obtained as the average of the time required for geometry optimization of the $15 \mathrm{Gd}^{\mathrm{III}}$ model systems presented in this work (Table 3). Furthermore, the relative timings required for geometry optimization with LC and SCRECPs, and the effect of the basis set employed for the description of ligand atoms, have been also estimated with the mPWB95 functional. As expected, the relative CPU times determined for the different density functionals increase in the order LSDA $<$ GGA $<$ hybrid GGA $<$ meta-GGA $<$ hybrid metaGGA. However, the effect of the density functional employed on the CPU times is not large, a geometry optimization with the TPSSh functional typically taking about twice the time required when using LSDA counterparts. A comparison of the CPU times required for geometry optimization with LC and SCRECPs (in combination with the mPWB95 functional and the 6-31G(d) basis set for the ligand atoms) shows that optimizations with the SCRECP take about 15 times longer than the LC counterparts, and about four times longer than MP2/LCRECP/6-31G(d) calculations. Concerning the effect of the basis set employed for the ligands on CPU times, the use of $6-31 \mathrm{G}(\mathrm{d}), 6-311 \mathrm{G}(\mathrm{d}), 6-311 \mathrm{G}(\mathrm{d}, \mathrm{p})$ or cc-pVDZ basis sets requires relatively similar timings. Thus, these basis sets, in combination with LCRECPs, appear to offer an adequate balance between accuracy and computational cost for the description of molecular geometries of $\mathrm{Ln}^{\mathrm{III}}$ complexes. 
Table 3. Relative CPU timings required for geometry optimization as a function of the density functional and basis set used normalized for the number of SCF and optimization cycles.

\begin{tabular}{lllll}
\hline Type & Functional & LC/6-31G(d) ${ }^{\mathrm{a}}$ & & $\mathrm{mPWB}^{2} / \mathrm{LC}^{\mathrm{c}}$ \\
\hline LSDA & SVWN & 1.2 & STO-3G & 0.37 \\
& SPL & 1.2 & $3-21 \mathrm{G}$ & 0.44 \\
GGA & BLYP & 1.4 & $6-31 \mathrm{G}$ & 0.53 \\
& G96LYP & 1.5 & $6-31 \mathrm{G}(\mathrm{d})$ & 1.0 \\
& mPWLYP & 1.5 & $6-311 \mathrm{G}$ & 0.95 \\
Hybrid-GGA & B3LYP & 1.8 & $6-311 \mathrm{G}(\mathrm{d})$ & 1.04 \\
& BH\&HLYP & 1.7 & $6-311 \mathrm{G}(\mathrm{d}, \mathrm{p})$ & 1.30 \\
& B3PW91 & 1.8 & $6-311+\mathrm{G}(\mathrm{d}, \mathrm{p})$ & 2.67 \\
Meta-GGA & BB95 & 2.1 & $\mathrm{cc}-\mathrm{pVDZ}$ & 1.32 \\
& mPWB95 & $1.6 / 24.2^{\mathrm{b}}$ & $\mathrm{cc}-\mathrm{pVTZ}$ & 5.95 \\
& TPSS & 2.2 & & \\
Hybrid meta-GGA & TPSSh & 2.4 & & \\
MP2 & & 6.8 & & \\
\hline
\end{tabular}

${ }^{a}$ CPU timing for HF/LCRECP/6-31G(d) taken as reference. ${ }^{b}$ Relative CPU timing obtained for mPWB95/SCRECP/6-31G(d). ${ }^{\mathrm{C}} \mathrm{CPU}$ timing for mPWB95/LCRECP/6-31G(d) taken as reference.

\subsection{CBS extrapolation}

The energies of selected model systems $(\mathbf{2}, \mathbf{4 , 8}, \mathbf{1 5})$ calculated with different density functionals (BH\&HLYP, mPWB95, TPSSh and wB97XD) and cc-pVxZ (x = D, T, Q, 5, in some cases 6) and aug-ccpVxZ ( $x=D, T$, in some cases $Q)$ basis sets are shown in Fig. 7 and Table 4. As expected, the energies obtained with the aug-cc-pVxZ basis set family are lower than those provided by the corresponding basis sets without diffuse functions ${ }^{[80]}$. The differences in energies for the two types of basis sets are large for double-, but they become small with the use of quadruple- basis sets. Analysis of the data obtained with the cc-pVxZ family according to Eq. (1) provided good fits, as judged by the high correlation coefficients obtained (typically >0.9999). All tested functionals provide similar energetic trends upon increasing basis set size and quality. The results shown in Table 4 indicate a relatively fast convergence of calculated energies to the CBS limit with basis set size, with deviations typically lower than $0.12,0.11,0.04$ and 0.008 a.u. for ccpVTZ, aug-cc-pVTZ, cc-pVQZ and cc-pV5Z respectively.

The energies of $\mathrm{Gd}^{\mathrm{III}}$ systems $\mathbf{2 , 4}$ and $\mathbf{1 5}$ were also extrapolated to the MP2/CBS limit employing Truhlar extrapolation scheme. The absolute energies calculated at the HF/aug-cc-pVXZ (X = D, T) and MP2/aug-cc$\mathrm{pVXZ}(\mathrm{X}=\mathrm{D}, \mathrm{T})$ theoretical levels can be found in Table 5. A comparison of the calculated MP2/aug-ccpVTZ energies and the CBS extrapolated values shows that the maximum difference is below 0.45 a.u, while the maximum difference between the double- $\zeta$ and the CBS values is 1.26 a.u. Similar differences between CBS extrapolated values and MP2/aug-cc-pVXZ $(X=D, T)$ energies have been observed recently ${ }^{[98]}$. The results shown in Table 4, Table 5 point to a much faster convergence of DFT energies with the CBS limit upon increasing basis set size and quality in comparison to MP2. 
Table 4. Absolute electronic energies for $\mathrm{Gd}^{\mathrm{III}}$ systems 2, 4, 8 and 15 calculated with different density functionals and LCRECP/aug-cc-pVXZ $(X=2-4)$ and LCRECP/cc-pVXZ basis sets $(X=2-6)$, and $Y(\infty)$ values obtained by fitting the cc-pVXZ data to Eq. (1). All values are given in a.u.

\begin{tabular}{|c|c|c|c|c|c|}
\hline & & 2 & 4 & 8 & 15 \\
\hline \multirow[t]{8}{*}{ BH\&HLYP } & cc-pVDZ & -930.0270 & -802.2183 & -1235.0547 & $-\mathrm{a}$ \\
\hline & cc-pVTZ & -930.2958 & -802.4656 & -1235.3883 & $-\mathrm{a}$ \\
\hline & cc-pVQZ & -930.3659 & -802.5272 & -1235.4716 & $-\mathrm{a}$ \\
\hline & cc-pV5Z & -930.3854 & -802.5450 & -1235.5004 & $-\mathrm{a}$ \\
\hline & aug-cc-pVDZ & -930.0886 & -802.2745 & -1235.1382 & $-\mathrm{a}$ \\
\hline & aug-cc-pVTZ & -930.3078 & -802.4766 & -1235.4034 & $-\mathrm{a}$ \\
\hline & aug-cc-pVQZ & $-^{\mathrm{a}}$ & -802.5324 & $-\mathrm{a}$ & $-\mathrm{a}$ \\
\hline & $Y(\infty)$ & -930.3917 & -802.5496 & -1235.5066 & $-\mathrm{a}$ \\
\hline \multirow[t]{9}{*}{ mPWB95 } & cc-pVDZ & -930.3495 & -802.4335 & -1158.9592 & -646.4948 \\
\hline & cc-pVTZ & -930.6271 & -802.6959 & -1159.2668 & -646.7150 \\
\hline & cc-pVQZ & -930.7042 & -802.7632 & -1159.3480 & -646.7711 \\
\hline & cc-pV5Z & -930.7298 & -802.7855 & -1159.3824 & -646.7893 \\
\hline & cc-pV6Z & $-^{\mathrm{a}}$ & $-^{\mathrm{a}}$ & $-^{\mathrm{a}}$ & -646.7933 \\
\hline & aug-cc-pVDZ & $-{ }^{\mathrm{a}}$ & $-^{\mathrm{a}}$ & -1159.0433 & $-^{\mathrm{a}}$ \\
\hline & aug-cc-pVTZ & -930.6410 & -802.7074 & -1159.2824 & -646.7254 \\
\hline & aug-cc-pVQZ & -930.7110 & -802.7692 & -1159.3557 & -646.7762 \\
\hline & $Y(\infty)$ & -930.7380 & -802.7914 & -1159.3897 & -646.7944 \\
\hline \multirow[t]{9}{*}{ TPSSh } & cc-pVDZ & -930.5711 & -802.6879 & -1235.5984 & -646.6344 \\
\hline & cc-pVTZ & -930.8277 & -802.9250 & -1235.9121 & -646.8353 \\
\hline & cc-pVQZ & -930.8996 & -802.9881 & -1235.9959 & -646.8890 \\
\hline & cc-pV5Z & -930.9187 & -803.0058 & $-^{\mathrm{a}}$ & -646.9037 \\
\hline & cc-pV6Z & $-{ }^{\mathrm{a}}$ & $-{ }^{\mathrm{a}}$ & $-^{\mathrm{a}}$ & -646.9064 \\
\hline & aug-cc-pVDZ & -930.6315 & -802.7436 & -1235.6778 & -646.6889 \\
\hline & aug-cc-pVTZ & -930.8406 & -802.9366 & -1235.9284 & -646.8462 \\
\hline & aug-cc-pVQZ & $-{ }^{\mathrm{a}}$ & $-^{\mathrm{a}}$ & $-^{\mathrm{a}}$ & -646.8937 \\
\hline & $Y(\infty)$ & -930.9266 & -803.0119 & -1236.0265 & -646.9083 \\
\hline \multirow[t]{9}{*}{ wB97XD } & cc-pVDZ & -930.3337 & -802.5161 & -1158.9313 & -646.5350 \\
\hline & cc-pVTZ & -930.5932 & -802.7563 & -1159.2220 & -646.7359 \\
\hline & cc-pVQZ & -930.6668 & -802.8216 & -1159.3004 & -646.7911 \\
\hline & cc-pV5Z & -930.6895 & -802.8418 & -1159.3304 & -646.8076 \\
\hline & cc-pV6Z & $-^{\mathrm{a}}$ & $-^{\mathrm{a}}$ & $-^{\mathrm{a}}$ & -646.8119 \\
\hline & aug-cc-pVDZ & -930.3931 & -802.5710 & -1159.0013 & -646.5882 \\
\hline & aug-cc-pVTZ & -930.6058 & -802.7680 & -1159.2361 & -646.7464 \\
\hline & aug-cc-pVQZ & $-^{\mathrm{a}}$ & -802.8282 & -1159.3304 & -646.7970 \\
\hline & $Y(\infty)$ & -930.6978 & -802.8483 & -1159.3379 & -646.8137 \\
\hline
\end{tabular}

\footnotetext{
${ }^{\text {a }}$ Not calculated.
} 

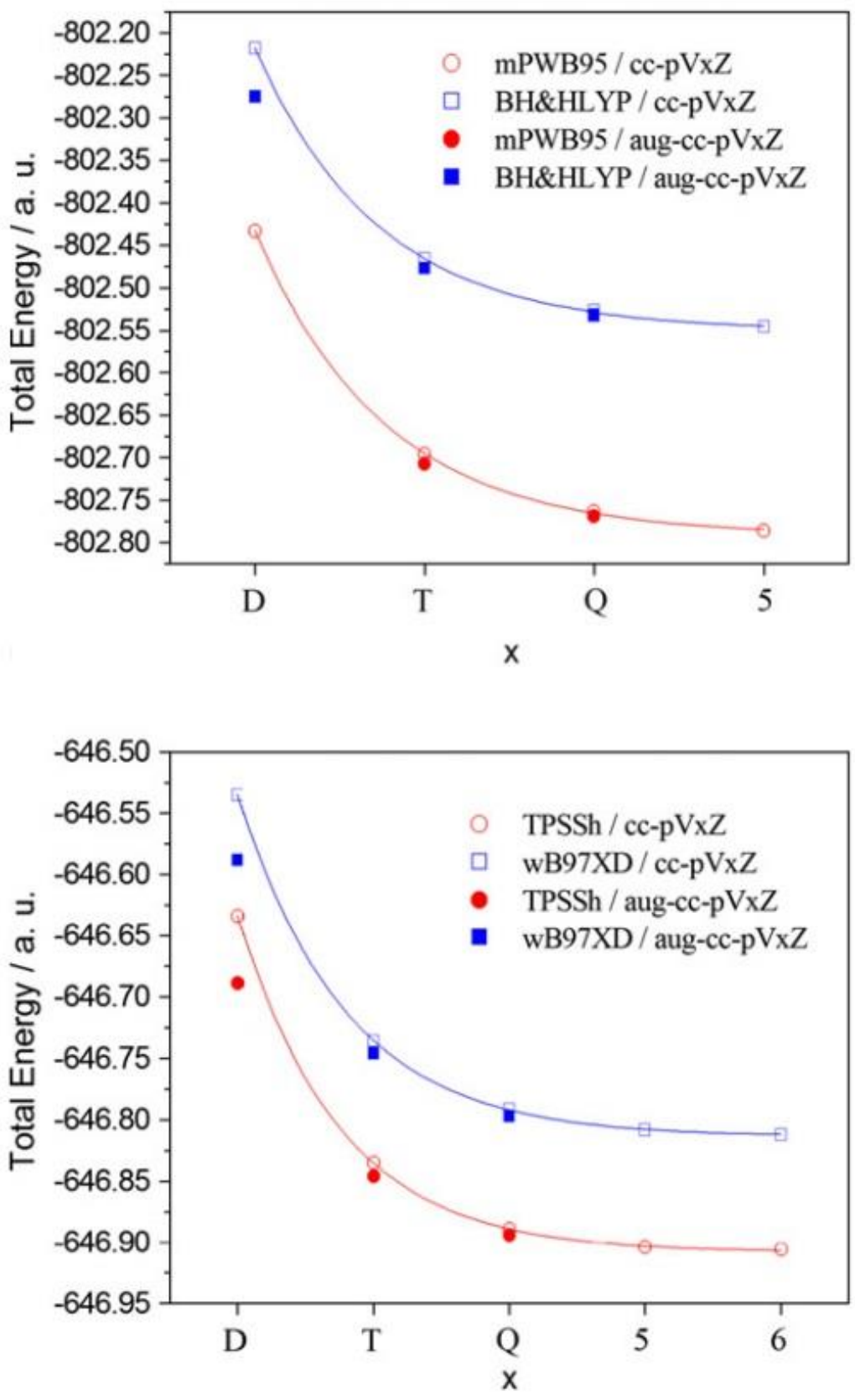

Fig. 7. DFT total energies for $\mathrm{Gd}^{\mathrm{III}}$ systems $\mathbf{4}$ (top) and $\mathbf{1 5}$ (bottom) as a function of basis set size and quality. The solid lines correspond to the best fit of the data according to Eq. (1).

Table 5. Absolute electronic energies calculated at the HF/LCRECP/aug-cc-pVXZ and MP2/LCRECP/aug-cc-pVXZ (X = 2 and 3) theoretical levels and MP2/CBS energies obtained using Truhlar extrapolation scheme for $\mathrm{Gd}^{\mathrm{III}}$ systems 2,4 and 15. All values are given in a.u.

\begin{tabular}{rlllll}
\hline & HF,$x=2$ & HF,$x=3$ & MP2, $x=2$ & MP2, $x=3$ & MP2/CBS \\
\hline $\mathbf{2}$ & -925.3167 & -925.5226 & -928.1771 & -928.9787 & -929.4453 \\
$\mathbf{4}$ & -798.1245 & -798.3139 & -800.6037 & -801.3240 & -801.7406 \\
$\mathbf{1 5}$ & -643.1712 & -643.3214 & -645.0846 & -645.6340 & -645.9485 \\
\hline
\end{tabular}




\subsection{Solvent effects}

Solvent effects (water) on the molecular geometries of the $15 \mathrm{Eu}^{\mathrm{III}}$ model systems presented in this work were evaluated at the mPWB95/SCRECP/6-31G(d) level with the aid of the IEFPCM model. Unfortunately, geometry optimizations of $\mathbf{1 4}$ performed in aqueous solution did not achieve convergence ${ }^{[99]}$. The average $\mathrm{Eu}-\mathrm{N}$ and $\mathrm{Eu}-\mathrm{O}$ bond distances calculated in the gas-phase and in solution for the remaining 14 systems are represented in Fig. 8 (see also Table 6). Our results show that the inclusion of bulk solvent effects has a relatively small impact in most of the calculated $\mathrm{Eu}-\mathrm{O}$ distances, while more important differences are observed for the $\mathrm{Eu}-\mathrm{N}$ bonds. Indeed, all $\mathrm{Eu}-\mathrm{N}$ distances experience an important lengthening upon inclusion of solvent effects $(0.027-0.067 \AA$ ). The large effect that the inclusion of solvent effects has on the Ln-N distances might be related again to a rather shallow potential energy surface, and reflects the importance of including the bulk solvent effects to obtain a more accurate description of the structures of $\mathrm{Ln}^{\mathrm{III}}$ complexes in water. A similar conclusion was reached previously from HF/LCRECP/3-21G (or 3-21G*) calculations performed on poliaminocarboxylate complexes, although in those cases the inclusion of solvent effects led to a shortening the $\mathrm{Ln}-\mathrm{N}$ bonds ${ }^{[32,100]}$.

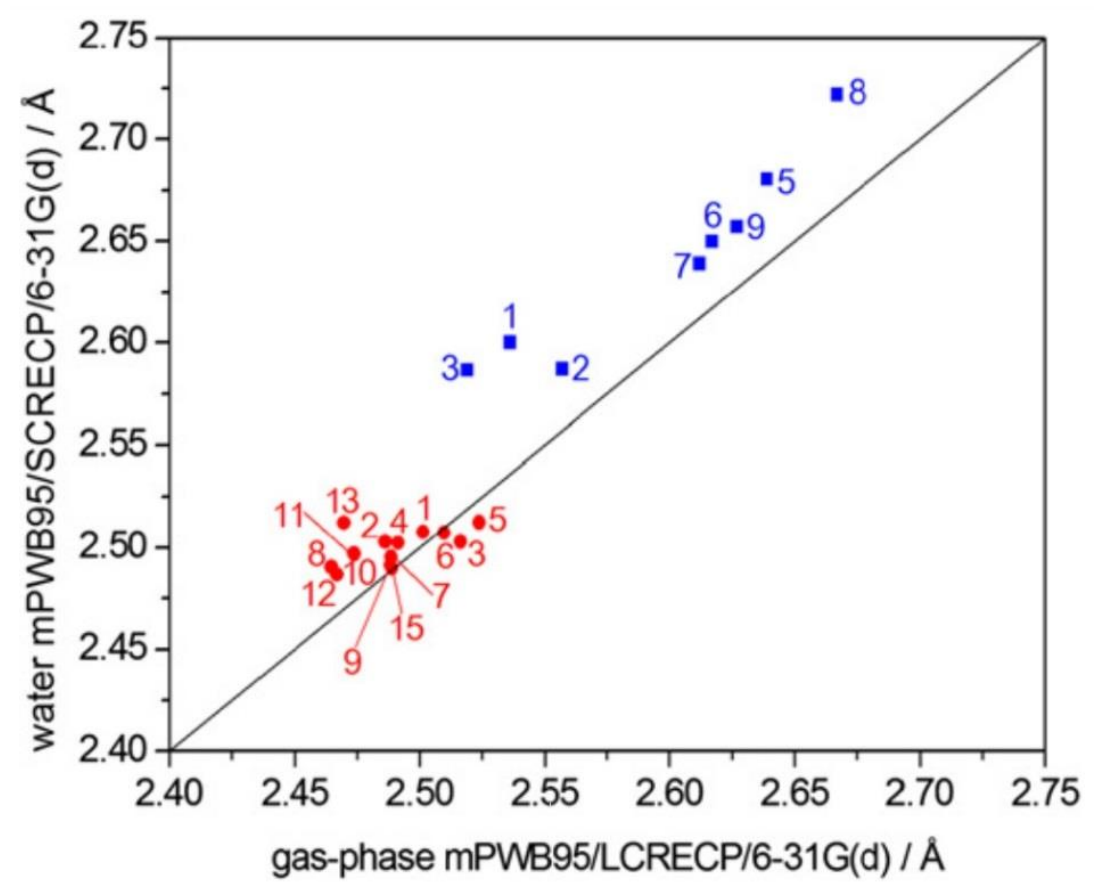

Fig. 8. Comparison of the mean Eu-donor distances $(\AA)$ at the mPWB95/SCRECP/6-31G(d) level in the gas-phase and in aqueous solution. The solid line represents a 1:1 relationship between the two sets of data. Data above the line indicate that $\mathrm{Ln}$-donor distances are longer in solution than in the gas-phase. Squares: $\mathrm{Eu}-\mathrm{N}$ distances; circles: Eu-O distances.

\subsection{Applications to larger systems}

Aiming to evaluate the effect of the density functional on the equilibrium geometries of larger lanthanide complexes, we performed full geometry optimizations of the $\left[\mathrm{Gd}(\mathbf{1 6})\left(\mathrm{H}_{2} \mathrm{O}\right)\right]^{3+},\left[\mathrm{Eu}(\mathbf{1 7})\left(\mathrm{H}_{2} \mathrm{O}\right)\right]^{-}$, $\left[\mathrm{Eu}(\mathbf{1 8})\left(\mathrm{H}_{2} \mathrm{O}\right)\right]^{2+},\left[\mathrm{Gd}(\mathbf{1 9})\left(\mathrm{H}_{2} \mathrm{O}\right)\right],[\mathrm{Gd}(\mathbf{2 0})],[\mathrm{Eu}(\mathbf{2 1})]^{3-}$ and $\left[\mathrm{Gd}(\mathbf{2 2})\left(\mathrm{H}_{2} \mathrm{O}\right)\right]^{2-}$ systems by using the G96LYP, B3LYP, mPWB95 and TPSSh functionals and the LCRECP/6-31G(d) basis set (Fig. 9). The X-ray structures of all these complexes, which have been reported in the literature ${ }^{[101-107]}$, were used as input geometries. Ligands 16-20 are based on macrocyclic platforms, while $\mathbf{2 1}$ and $\mathbf{2 2}$ are non-macrocyclic ligands. 
Table 6. Mean Eu-N and Eu-O bond distances $(\AA)$ obtained at the mPWB95/SCRECP/6-31G(d) level in the gas-phase and in aqueous solution.

\begin{tabular}{cllll}
\hline System & Eu-N (gas-phase) & $\mathrm{Eu}-\mathrm{N}$ (water) & $\mathrm{Eu}-\mathrm{O}$ (gas-phase) & $\mathrm{Eu}-\mathrm{O}$ (water) \\
\hline $\mathbf{1}$ & 2.536 & 2.600 & 2.501 & 2.508 \\
$\mathbf{2}$ & 2.557 & 2.587 & 2.486 & 2.503 \\
$\mathbf{3}$ & 2.519 & 2.586 & 2.516 & 2.503 \\
$\mathbf{4}$ & - & - & 2.592 & 2.502 \\
$\mathbf{5}$ & 2.639 & 2.681 & 2.524 & 2.513 \\
$\mathbf{6}$ & 2.617 & 2.650 & 2.510 & 2.507 \\
$\mathbf{7}$ & 2.612 & 2.639 & 2.489 & 2.495 \\
$\mathbf{8}$ & 2.667 & 2.722 & 2.465 & 2.490 \\
$\mathbf{9}$ & 2.627 & 2.657 & 2.488 & 2.491 \\
$\mathbf{1 0}$ & - & - & 2.474 & 2.497 \\
$\mathbf{1 1}$ & - & - & 2.474 & 2.497 \\
$\mathbf{1 2}$ & - & - & 2.467 & 2.487 \\
$\mathbf{1 3}$ & - & - & 2.470 & 2.512 \\
$\mathbf{1 5}$ & - & - & 2.489 & 2.490 \\
\hline
\end{tabular}

Table 7. Mean Ln-N and Ln-O bond distances ( $\mathrm{A})$ obtained for complexes with ligands 16-22.

\begin{tabular}{llllllll}
\hline & & G96LYP & B3LYP & TPSSh & mPWB95 (vacuo) & mPWB95 (solution) & X-ray \\
\hline $\mathbf{1 6}$ & Ln-N & 2.759 & 2.743 & 2.699 & 2.705 & 2.667 & 2.644 \\
& Ln-O & 2.453 & 2.433 & 2.427 & 2.439 & 2.442 & 2.391 \\
$\mathbf{1 7}$ & Ln-N & 2.792 & 2.777 & 2.725 & 2.725 & 2.687 & 2.677 \\
& Ln-O & 2.446 & 2.428 & 2.424 & 2.434 & 2.452 & 2.400 \\
$\mathbf{1 8}$ & Ln-N & 2.834 & 2.784 & 2.754 & 2.759 & 2.708 & 2.703 \\
& Ln-O & 2.457 & 2.438 & 2.433 & 2.447 & 2.453 & 2.380 \\
$\mathbf{1 9}$ & Ln-N & 2.759 & 2.732 & 2.684 & 2.685 & 2.653 & 2.639 \\
& Ln-O & 2.453 & 2.388 & 2.385 & 2.390 & 2.430 & 2.377 \\
$\mathbf{2 0}$ & Ln-N & 2.757 & 2.732 & 2.706 & 2.719 & 2.702 & 2.657 \\
& Ln-O & 2.477 & 2.463 & 2.441 & 2.449 & 2.467 & 2.427 \\
$\mathbf{2 1}$ & Ln-N & 3.263 & 2.977 & 2.886 & 2.890 & 2.760 & 2.671 \\
& Ln-O & 2.399 & 2.410 & 2.415 & 2.424 & 2.430 & 2.371 \\
$\mathbf{2 2}$ & Ln-N & 2.753 & 2.744 & 2.689 & 2.702 & 2.650 & 2.709 \\
& Ln-O & 2.486 & 2.464 & 2.459 & 2.466 & 2.469 & 2.393 \\
\hline
\end{tabular}

Additionally, we also evaluated the bulk solvent effects of the optimized geometries of these systems at the mPWB95/LCRECP/6-31G(d) level. The results are shown in Table 7, while the representative cases of $\left[\mathrm{Eu}(\mathbf{1 7})\left(\mathrm{H}_{2} \mathrm{O}\right)\right]^{-}$and $[\mathrm{Eu}(\mathbf{2 1})]^{3-}$ are shown in Fig. 10. Our results confirm the calculations performed on model systems 1-15 in the sense that MPWB95 and TPSSh functionals provide very similar distances of the metal coordination environments, while G96LYP and B3LYP give substantially longer Ln-N distances. The overestimation of Ln-N bonds of B3LYP compared to mPWB95 and TPSSh is particularly important in the case of $[\mathrm{Eu}(\mathbf{2 1})]^{3-}$, probably as a result lower rigidity of the ligand in comparison to macrocyclic ligands 1620 and the non-macrocyclic ligand containing cyclohexyl units 22. The four functionals provide however 
quite similar Ln-O distances. Including the bulk solvent effects with the aid of the IEFPCM model provokes an important shortening of the Ln-N distances by $0.017-0.130 \AA$, while the $\mathrm{Ln}-\mathrm{O}$ distances slightly increase (0.003-0.040 $\AA$ ). This is in line with previous investigations on $\mathrm{Ln}^{\mathrm{III}}$ polyaminocarboxylates, which showed that the inclusion of solvent effects provokes a substantial shortening of the $\mathrm{Ln}-\mathrm{N}$ distances ${ }^{[32,100]}$. As a general trend, the $\mathrm{Ln}-\mathrm{N}$ bond distances calculated in solution are closer to the distances observed in the $\mathrm{X}$ ray crystal structures than those obtained in the gas-phase. Although the distances observed in the solid state might differ from the actual distances in solution, these results show that the $\mathrm{Ln}-\mathrm{N}$ distances become shorter in the condensed phase compared to the gas-phase. This effect can be partially ascribed to an overbinding of the negatively charged donor atoms of the ligand in the gas-phase. The introduction of solvent effects weakens the Ln-O bonds, which results in a concomitant shortening of the $\mathrm{Ln}-\mathrm{N}$ distances ${ }^{[108]}$.<smiles>NC(=O)CN1CCN(CC(N)=O)CCN(CC(N)=O)CCN(CC(N)=O)CC1</smiles>

16<smiles>NC(=O)CN1CCN(CC(N)=O)CCN(Cc2cc([N+](=O)[O-])ccc2[O-])CCN(CC(N)=O)CC1</smiles>

18<smiles>O=C([O-])CN1CCOCCN(CC(=O)[O-])CCOCCN(CC(=O)[O-])CCOCC1</smiles>

20

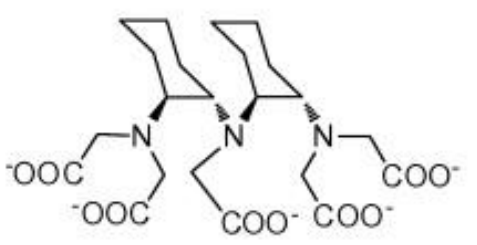

22<smiles>O=C(O)CCC(C(=O)[O-])N1CCN(C(CCC(=O)O)C(=O)[O-])CCN(C(CCC(=O)O)C(=O)[O-])CCN(C(CCC(=O)O)C(=O)[O-])CC1</smiles><smiles>O=C([O-])CN1CCN(CC(=O)[O-])CCN(Cc2cc(N3CCOCC3)ccn2)CCN(CC(=O)[O-])CC1</smiles>

19<smiles>O=C([O-])CN(CCNCCN(CC(=O)[O-])CC(=O)[O-])CC(=O)[O-]</smiles>

21

Fig. 9. Macrocyclic and non-macrocyclic ligands for $\mathrm{Ln}^{\mathrm{III}}$ complexation investigated in this work. 

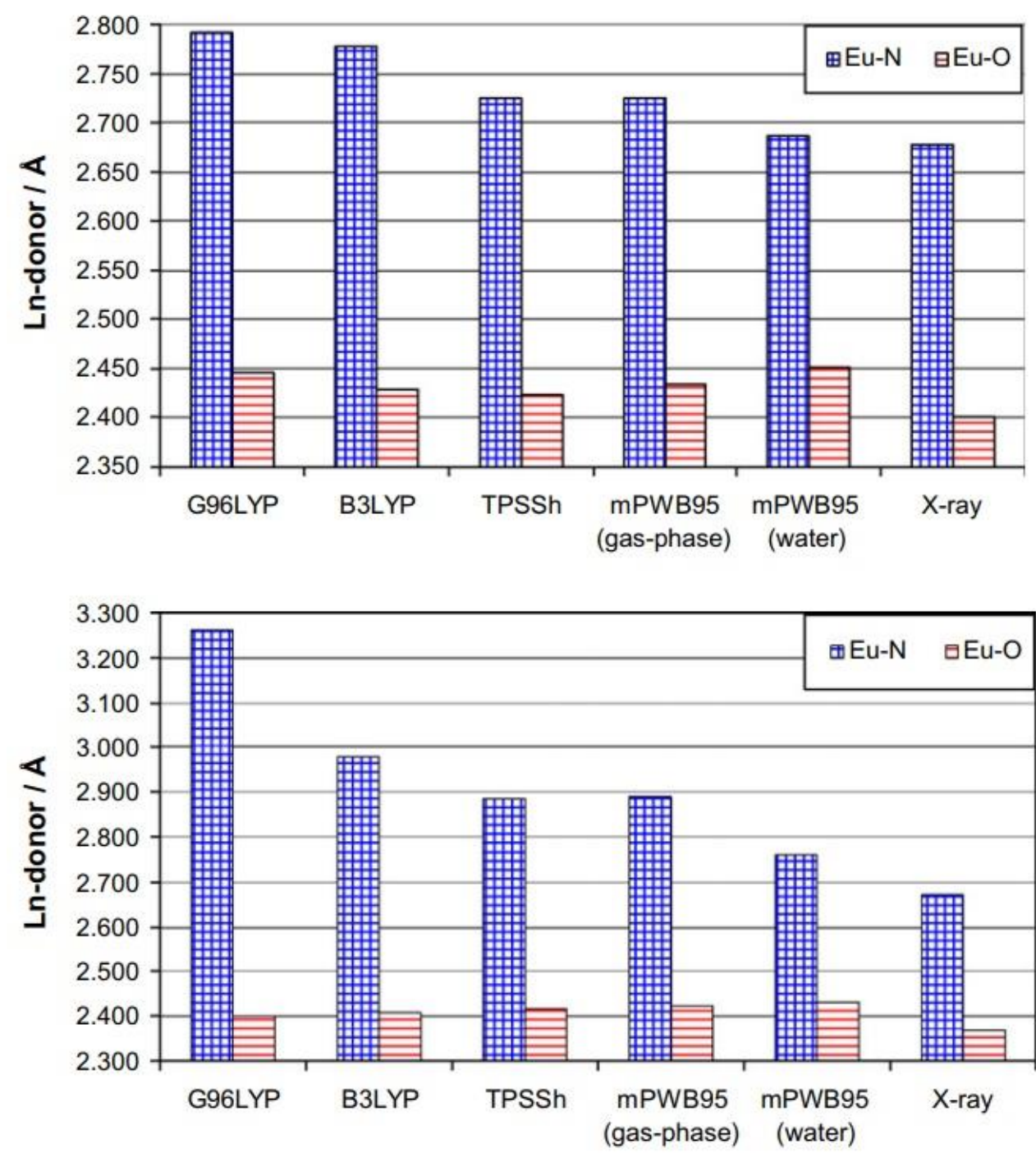

Fig. 10. Average Ln-donor distances $(\AA)$ obtained for $\left[\mathrm{Eu}(\mathbf{1 7})\left(\mathrm{H}_{2} \mathrm{O}\right)\right]^{-}$(top) and $[\mathrm{Eu}(\mathbf{2 1})]^{3-}$ (bottom) by using different density functionals and corresponding values observed experimentally in the solid state. Blue: $\mathrm{Eu}-\mathrm{N}$ distances; Red: Eu-O distances. (For interpretation of the references to color in this figure legend, the reader is referred to the web version of this article.)

\section{Conclusions}

We have evaluated the performance of 15 commonly available functionals for geometry optimization of 15 model systems containing binding motifs often present in systems with potential biomedical application. Our choice of MP2/LCRECP/6-31G(d) geometries as the compromise benchmark is open to criticism, as evidence exists that many of the higher rung DFT functionals are more accurate than MP2 ${ }^{[83]}$. However, it is unlikely that the relative performance of DFT functionals observed in this work would significantly change by a different choice of the benchmark. The results show that meta-GGA functionals such as mPWB95, BB95 and TPSS, as well as the hybrid meta-GGA functional TPSSh, perform substantially better than the hybrid GGA and GGA functionals investigated. Hybrid GGA functionals BH\&HLYP and B3PW91 also provide reasonably good results, and perform substantially better than B3LYP, while functionals based on the LSDA approximation and GGA functionals should not be used for obtaining accurate geometries of $\mathrm{Ln}^{\text {III }}$ complexes. Calculations performed on different $\mathrm{Ln}^{\text {III }}$ polyaminocarboxylate complexes with both macrocyclic and acyclic ligands confirm these results. 
The use of LCRECPs of the Stuttgart family provides somewhat longer $\mathrm{Ln}^{\text {III }}$-donor distances than the SCRECP approach. However, the shortening of bond lengths is relatively small, the average contraction of bond distances amounting to $0.033 \AA$ for the systems investigated in this work. Considering the high computational cost of SCRECP calculations, and the relatively large size of the complexes used for bioanalytical and biomedical applications, the LCREP approach appears to be the most practical choice for calculating the geometries of this kind of systems. Concerning the basis sets used for the description of the ligand atoms, polarized double- or triple- $\zeta$ basis sets such as $6-31 \mathrm{G}(\mathrm{d}), 6-311 \mathrm{G}(\mathrm{d}), 6-311 \mathrm{G}(\mathrm{d}, \mathrm{p})$ and ccpVDZ basis sets appear to offer an adequate balance between accuracy and computational cost. Finally, the calculations reported in this paper highlight the importance of including solvent effects to obtain a more accurate description of the structures of $\mathrm{Ln}^{\mathrm{III}}$ complexes in solution.

\section{Acknowledgements}

The authors thank Ministerio de Educación y Ciencia (MEC, CTQ2009-10721), Fondo Europeo de Desarrollo Regional (FEDER, CTQ2009-10721) and Xunta de Galicia (IN845B-2010/063) for financial support. M.R.-F. thanks Ministerio de Educación y Ciencia (FPU program) for a predoctoral fellowship. A.R.-S. thanks Xunta de Galicia (María Barbeito program) for a predoctoral fellowship.

\section{Supplementary material}

Plots showing the unsigned mean error (UME) values $(\AA)$ obtained for the $\mathrm{Gd}^{\mathrm{III}}$ and $\mathrm{Tb}^{\mathrm{III}}$ model systems investigated in this work, Cartesian coordinates of 1-15 optimized at the MP2/LCRECP/6-31G(d) level, and Cartesian coordinates of $\left[\mathrm{Gd}(\mathbf{1 6})\left(\mathrm{H}_{2} \mathrm{O}\right)\right]^{3+},\left[\mathrm{Eu}(\mathbf{1 7})\left(\mathrm{H}_{2} \mathrm{O}\right)\right]^{-},\left[\mathrm{Eu}(\mathbf{1 8})\left(\mathrm{H}_{2} \mathrm{O}\right)\right]^{-},\left[\mathrm{Gd}(\mathbf{1 9})\left(\mathrm{H}_{2} \mathrm{O}\right)\right],[\mathrm{Gd}(\mathbf{2 0})]$, $[\mathrm{Eu}(\mathbf{2 1})]^{3-}$ and $\left[\mathrm{Gd}(\mathbf{2 2})\left(\mathrm{H}_{2} \mathrm{O}\right)\right]^{2-}$ optimized at the mPWB95/LCRECP/6-31G(d) level. Supplementary data associated with this article can be found, in the online version, at https://doi.org/10.1016/j.comptc.2012.08.020.

\section{References}

[1] D. Parker, R.S. Dickins, H. Puschmann, C. Crossland, J.A.K. Howard, Being excited by lanthanide coordination complexes: aqua species, chirality, excited-state chemistry, and exchange dynamics, Chem. Rev. 102 (2002) 1977-2010.

[2] P. Caravan, J.J. Ellinson, T.J. McMurry, R.B. Lauffer, Gadolinium(III) chelates as MRI contrast agents: structure, dynamics, and applications, Chem. Rev. 99 (1999) 2293-2352.

[3] A.E. Merbach, E. Tóth, The Chemistry of Contrast Agents in Medical Magnetic Resonance Imaging, Wiley, New York, 2001.

[4] L.M. De Leon-Rodriguez, A.J.M. Lubag, C.R. Malloy, G.V. Martinez, R.J. Gillies, A.D. Sherry, Responsive MRI agents for sensing metabolism in vivo, Acc. Chem. Res. 42 (2009) 948-957.

[5] K.W.Y. Chan, W.T. Wong, Small molecular gadolinium(III) complexes as MRI contrast agents for diagnostic imaging, Coord. Chem. Rev. 251 (2007) 2428-2451.

[6] E. Terreno, D.D. Castelli, A. Viale, S. Aime, Challenges for molecular magnetic resonance imaging, Chem. Rev. 110 (2010) 3019-3042. 
[7] S. Liu, Bifunctional coupling agents for radiolabeling of biomolecules and target-specific delivery of metallic radionuclides, Adv. Drug Deliv. Rev. 60 (2008) 1347-1370.

[8] F. Roesch, Radiolanthanides in endoradiotherapy: an overview, Radiochim. Acta 95 (2007) 303-311.

[9] W.A. Volkert, T.J. Hoffman, Therapeutic radiopharmaceuticals, Chem. Rev. 99 (1999) 2269-2292.

[10] M.F. Tweedle, Peptide-targeted diagnostics and radiotherapeutics, Acc. Chem. Res. 42 (2009) 958-968.

[11] J.C.G. Bünzli, Lanthanide luminescence for biomedical analyses and imaging, Chem. Rev. 110 (2010) 2729-2755.

[12] D. Geissler, L.J. Charbonnière, R.F. Ziessel, N.G. Butlin, H.G. Löhmannsröben, N. Hildebrandt, Quantum dot biosensors for ultrasensitive multiplexed diagnostics, Angew. Chem. Int. Ed. 49 (2010) 13961401.

[13] S. Cheng, L. Abramova, G. Saab, G. Turabelidze, P. Patel, M. Arduino, T. Hess, A. Kallen, M. Jhung, Nephrogenic fibrosing dermopathy associated with exposure to gadolinium-containing contrast agent, JAMA 297 (2007) 1542-1544.

[14] E. Brücher, A.D. Sherry, Stability and toxicity of contrast agents, in: E. Tóth, A.E. Merbach (Eds.), The Chemistry of Contrast Agents in Medical Magnetic Resonance Imaging, Wiley, New York, 2001.

[15] S.A. Cotton, Establishing coordination numbers for the lanthanides in simple complexes, C.R. Chim. 8 (2005) 129-145.

[16] I. Persson, P. D’Angelo, S. De Panfilis, M. Sandström, L. Eriksson, Hydration of lanthanoid(III) ions in aqueous solution and crystalline hydrates studied by EXAFS spectroscopy and crystallography: the myth of the "gadolinum break", Chem. Eur. J. 14 (2008) 3056-3066.

[17] Y. Kataoka, P. Dharam, H. Miyake, T. Yaita, E. Miyoshi, H. Mori, S. Tsukamoto, H. Tatewaki, S. Shinoda, H. Tsukube, Experimental and theoretical approaches toward anion-responsive tripod-lanthanide complexes: mixed-donor ligand effects on lanthanide complexation and luminescence sensing profiles, Chem. Eur. J. 14 (2008) 5258-5266.

[18] A. Villa, U. Cosentino, D. Pitea, G. Moro, A. Maiocchi, Force field parametrization for gadolinium complexes based on ab initio potential energy surface calculations, J. Phys. Chem. A 104 (2000) 3421-3429.

[19] E.S. Henriques, M. Bastos, C.F.G.C. Geraldes, M.J. Ramos, Computational approaches to the study of some lanthanide(III)-polyazamacrocyclic chelates for magnetic resonance imaging, Int. J. Quantum Chem. 73 (1999) 237-248.

[20] U. Cosentino, G. Moro, D. Pitea, A. Villa, P.C. Fantucci, A. Maiocchi, F. Uggeri, Ab initio investigation of gadolinium complexes with polyamino carboxylate ligands and force fields parametrization of metal-ligand interactions, J. Phys. Chem. A 102 (1998) 4606-4614.

[21] A.P. Souza, F.A.A. Paz, R.O. Freire, L.D. Carlos, O.L. Malta, S. Alves, G.F. De Sá Jr., Synthesis, crystal structure, and modelling of a new tetramer complex of Europium, J. Phys. Chem. B 111 (2007) 92289238.

[22] M.O. Rodrigues, N.B.C. Júnior, C.A. de Simone, A.A.S. Araújo, A.M. Brito-Silva, F.A.A. Paz, M.E. de Mesquita, S.A. Júnior, R.O. Freire, Theoretical and experimental studies of the photoluminescent properties of the coordination polymer $\left[\mathrm{Eu}(\mathrm{DPA})(\mathrm{HDPA})\left(\mathrm{H}_{2} \mathrm{O}\right)_{2}\right] \cdot 4 \mathrm{H}_{2} \mathrm{O}$, J. Phys. Chem. B 112 (2008) 4204-4212. 
[23] D. Maffeo, M. Lampropoulou, M. Fardis, Y.G. Lazarou, I.M. Mavridis, D.A.I. Mavridou, E. Urso, H. Pratsinis, D. Kletsas, K. Yannakopoulou, Novel polycarboxylated EDTA-type cyclodextrins as ligands for lanthanide binding: study of their luminescence, relaxivity properties of Gd(III) complexes, and PM3 theoretical calculations, Org. Biomol. Chem. 8 (2010) 1910-1921.

[24] R.O. Freire, G.B. Rocha, A.M. Simas, Sparkle model for the calculation of lanthanide complexes: AM1 parameters for Eu(III), Gd(III), and Tb(III), Inorg. Chem. 44 (2005) 3299-3310.

[25] R.O. Freire, N.B. da Costa Jr., G.B. Rocha, A.M. Simas, Sparkle/PM3 parameters for the modeling of neodymium(III), promethium(III), and samarium(III) complexes, J. Chem. Theory Comput. 3 (2007) 15881596.

[26] C. Boehme, G. Wipff, Thiophosphoryl complexes of trivalent lanthanide cations: importance of counterions and stoichiometry for binding energies. A theoretical study, J. Phys. Chem. A 103 (1999) 60236029 .

[27] C. Boehme, G. Wipff, Dithiophosphinate complexes of trivalent lanthanide cations: consequences of counterions and coordination number for binding energies and selectivity, Inorg. Chem. 38 (1999) 57345741

[28] C. Boehme, G. Wipff, The energetic and structural effects of steric crowding in phosphate and dithiophosphinate complexes of lanthanide cations M3+: a computational study, Chem. Eur. J. 7 (2001) 1398-1407.

[29] B. Coupez, C. Boehme, G. Wipff, Interaction of bifunctional carbonyl and phosphoryl ligands with M3+ lanthanide cations: how strong is the bidentate effect? The role of ligand size and counterions investigated by quantum mechanics, Phys. Chem. Chem. Phys. 4 (2002) 5716-5729.

[30] M. Baaden, M. Bugard, C. Boehme, G. Wipff, Lanthanide cation binding to a phosphoryl-calix[4]arene: the importance of solvent and counterions investigated by molecular dynamics and quantum mechanical simulations, Phys. Chem. Chem. Phys. 3 (2001) 1317-1325.

[31] C. Boehme, B. Coupez, G. Wipff, Interaction of $\mathrm{M}^{3+}$ lanthanide cations with diamide ligands and their thio analogues: a quantum mechanics study of monodentate vs bidentate binding, counterion effects, and ligand protonation, J. Phys. Chem. A 106 (2002) 6487-6498.

[32] U. Cosentino, A. Villa, D. Pitea, G. Moro, V. Barone, A. Maiocchi, Conformational characterization of lanthanide(III)-DOTA complexes by ab initio investigation in vacuo and in aqueous solution, J. Am. Chem. Soc. 124 (2002) 4901-4909.

[33] C. Platas-Iglesias, A. Roca-Sabio, M. Regueiro-Figueroa, D. Esteban-Gómez, A. de Blas, T. RodríguezBlas, Applications of density functional theory (DFT) to investigate the structural, spectroscopic and magnetic properties of lanthanide(III) complexes, Curr. Inorg. Chem. 1 (2011) 91-116.

[34] C. Adamo, P.A. Maldivi, A theoretical study of bonding in lanthanide trihalides by density functional methods, J. Phys. Chem. A 102 (1998) 6812-6820.

[35] L. Petit, A. Borel, C. Daul, P. Maldivi, C. Adamo, A theoretical characterization of covalency in rare earth complexes through their absorption electronic properties: f-f transitions, Inorg. Chem. 45 (2006) 7382 7388.

[36] T. Toraishi, S. Nagasaki, S. Tanaka, A theoretical study on molecular structure of Eu(III)-salicylate complexes in aqueous system, J. Mol. Struct. (THEOCHEM) 757 (2005) 87-97. 
[37] G.V. Girichev, N.I. Giricheva, A. Haaland, N.P. Kuzmina, S. Samdal, T.N. Strenalyuk, N.V. Tverdova, I.G. Zaitseva, Molecular structures of tris(dipivaloylmethanato) complexes of the lanthanide metals, $\operatorname{Ln}(\mathrm{dpm})_{3}$, studied by gas electron diffraction and density functional theory calculations: a comparison of the $\mathrm{Ln}-\mathrm{O}$ bond distances and enthalpies in $\mathrm{Ln}(\mathrm{dpm})_{3}$ complexes and the cubic sesquioxides, $\operatorname{Ln}_{2} \mathrm{O}_{3}$, Inorg. Chem. 45 (2006) 5179-5186.

[38] L.N. Puntus, K.A. Lyssenko, I.S. Pekareva, M.Y. Antipin, Characterisation of geometric isomers of europium chlorides with 2,2'-bipyridine based on X-ray diffraction, luminescence and quantum chemical data, Mol. Phys. 108 (2010) 557-572.

[39] C. Núñez, M. Mato-Iglesias, R. Bastida, A. Macías, P. Pérez-Lourido, C. PlatasIglesias, L. Valencia, Solid-state and solution structure of lanthanide(III) complexes with a flexible Py-N6 macrocyclic ligand full text, Eur. J. Inorg. Chem. 8 (2009) 1086-1095.

[40] L.J. Charbonniére, R. Schurhammer, S. Mameri, G. Wipff, R.F. Ziessel, Photophysical and structural impact of phosphorylated anions associated to lanthanide complexes in water, Inorg. Chem. 44 (2005) 71517160 .

[41] H. Heiberg, O. Gropen, J.K. Laerdahl, O. Swang, U. Wahlgren, The performance of density functional theory for $\mathrm{LnF}(\mathrm{Ln}=\mathrm{Nd}, \mathrm{Eu}, \mathrm{Gd}, \mathrm{Yb})$ and $\mathrm{YbH}$, Theor. Chem. Acc. 110 (2003) 118-125.

[42] B. Kvamme, M.C.F. Wander, A.E. Clark, The role of basis set superposition error in water addition reactions to Ln(III) cations, Int. J. Quantum. Chem. 109 (2009) 2474-2481.

[43] A.E. Clark, Density functional and basis set dependence of hydrated Ln(III) properties, J. Chem. Theory Comput. 4 (2008) 708-718.

[44] A. Dinescu, A.E. Clark, Thermodynamic and structural features of aqueous Ce(III), J. Phys. Chem. A 112 (2008) 11198-11206.

[45] M. Purgel, Z. Baranyai, A. de Blas, T. Rodríguez-Blas, I. Banyai, C. PlatasIglesias, I. Toth, An NMR and DFT investigation on the conformational properties of lanthanide(III) 1,4,7,10-tetraazacyclododecane1,4,7,10- tetraacetate analogues containing methylenephosphonate pendant arms, Inorg. Chem. 49 (2010) $4370-4382$.

[46] F. Mayer, C. Platas-Iglesias, L. Helm, J.A. Peters, K. Djanashvili, ${ }^{17}$ O NMR and density functional theory study of the dynamics of the carboxylate groups in DOTA complexes of lanthanides in aqueous solution, Inorg. Chem. 51 (2012) 170-178.

[47] M. Regueiro-Figueroa, D. Esteban-Gómez, A. de Blas, T. Rodríguez-Blas, C. Platas-Iglesias, Structure and dynamics of lanthanide(III) complexes with an N-Alkylated do3a ligand (H3do3a $=1,4,7,10-$ tetraazacyclododecane-1,4,7- triacetic acid): a combined experimental and DFT study, Eur. J. Inorg. Chem. 23 (2010) 3586-3595.

[48] M. Mato-Iglesias, T. Rodriguez-Blas, C. Platas-Iglesias, M. Starck, P. Kadjane, R. Ziessel, L. Charbonnière, Solution structure and dynamics, stability, and NIR emission properties of lanthanide complexes with a carboxylated bispyrazolylpyridyl ligand, Inorg. Chem. 48 (2009) 1507-1518.

[49] M.C. Fernández-Fernández, R. Bastida, A. Macías, P. Pérez-Lourido, C. PlatasIglesias, L. Valencia, Lanthanide(III) complexes with a tetrapyridine pendantarmed macrocyclic ligand: ${ }^{1} \mathrm{H}$ NMR structural determination in solution, Xray diffraction, and density-functional theory calculations, Inorg. Chem. 45 (2006) 4484-4496. 
[50] A. Roca-Sabio, M. Mato-Iglesias, D. Esteban-Gómez, E. Tóth, A. de Blas, C. Platas-Iglesias, T. Rodríguez-Blas, Macrocyclic receptor exhibiting unprecedented selectivity for light lanthanides, J. Am. Chem. Soc. 131 (2009) 3331-3869.

[51] M. Regueiro-Figueroa, B. Bensenane, E. Ruscsák, D. Esteban-Gómez, L.J. Charbonnière, G. Tircsó, I. Tóth, A. de Blas, T. Rodríguez-Blas, C. PlatasIglesias, Lanthanide dota-like complexes containing a picolinate pendant: structural entry for the design of LnIII-based luminescent probes, Inorg. Chem. 50 (2011) $4125-4141$.

[52] L.M.P. Lima, A. Lecointre, J.F. Morfin, A. de Blas, D. Visvikis, L.J. Charbonnière, C. Platas-Iglesias, R. Tripier, Positively charged lanthanide complexes with cyclen-based ligands: synthesis, solid-state and solution structure, and fluoride interaction, Inorg. Chem. 50 (2011) 12508-12521.

[53] M. Mato-Iglesias, A. Roca-Sabio, Z. Palinkas, D. Esteban-Gómez, C. PlatasIglesias, E. Toth, A. de Blas, T. Rodriguez-Blas, Lanthanide complexes based on a 1,7-diaza-12-crown-4 platform containing picolinate pendants: a new structural entry for the design of magnetic resonance imaging contrast agents, Inorg. Chem. 47 (2008) 7840-7851.

[54] M.J. Frisch, G.W. Trucks, H.B. Schlegel, G.E. Scuseria, M.A. Robb, J.R. Cheeseman, G. Scalmani, V. Barone, B. Mennucci, G.A. Petersson, H. Nakatsuji, M. Caricato, X. Li, H.P. Hratchian, A.F. Izmaylov, J. Bloino, G. Zheng, J.L. Sonnenberg, M. Hada, M. Ehara, K. Toyota, R. Fukuda, J. Hasegawa, M. Ishida, T. Nakajima, Y. Honda, O. Kitao, H. Nakai, T. Vreven Jr., J.A. Montgomery, J.E. Peralta, F. Ogliaro, M. Bearpark, J.J. Heyd, E. Brothers, K.N. Kudin, V.N. Staroverov, R. Kobayashi, J. Normand, K. Raghavachari, A. Rendell, J.C. Burant, S.S. Iyengar, J. Tomasi, M. Cossi, N. Rega, N.J. Millam, M. Klene, J.E. Knox, J.B. Cross, V. Bakken, C. Adamo, J. Jaramillo, R. Gomperts, R.E. Stratmann, O. Yazyev, A.J. Austin, R. Cammi, C. Pomelli, J.W. Ochterski, R.L. Martin, K. Morokuma, V.G. Zakrzewski, G.A. Voth, P. Salvador, J.J. Dannenberg, S. Dapprich, A.D. Daniels, Ö. Farkas, J.B. Foresman, J.V. Ortiz, J. Cioslowski, D.J. Fox, Gaussian 09, Revision A.01, Gaussian, Inc., Wallingford, CT, 2009.

[55] J.C. Slater, Quantum Theory of Molecules and Solids: The Self-Consistent Field for Molecules and Solids, McGraw-Hill, New York, 1974.

[56] S.H. Vosko, L. Wilk, M. Nusair, Accurate spin-dependent electron liquid correlation energies for local spin density calculations: a critical analysis, Can. J. Phys. 58 (1980) 1200-1211.

[57] J.P. Perdew, A. Zunger, Self-interaction correction to density-functional approximations for manyelectron systems, Phys. Rev. B 23 (1981) 5048-5079.

[58] A.D. Becke, Density-functional exchange-energy approximation with correct asymptotic behavior, Phys. Rev. A 38 (1988) 3098-3100.

[59] C. Lee, W. Yang, R.G. Parr, Development of the Colle-Salvetti correlationenergy formula into a functional of the electron density, Phys. Rev. B 37 (1988) 785-789.

[60] P.M.W. Gill, A new gradient-corrected exchange functional, Mol. Phys. 89 (1996) 433-445.

[61] C. Adamo, V. Barone, Implementation and validation of the Lacks-Gordon exchange functional in conventional density functional and adiabatic connection methods, J. Comput. Chem. 19 (1998) 418-429.

[62] C. Adamo, V. Barone, Exchange functionals with improved long-range behavior and adiabatic connection methods without adjustable parameters: the mPW and mPW1PW models, J. Chem. Phys. 108 (1998) 664-675. 
[63] A.D. Becke, Density-functional thermochemistry. III. The role of exact exchange, J. Chem. Phys. 98 (1993) 5648-5652.

[64] A.D. Becke, A new mixing of Hartree-Fock and local-density-functional theories, J. Chem. Phys. 98 (1993) 1372-1377.

[65] J.P. Perdew, K. Burke, Y. Wang, Generalized gradient approximation for the exchange-correlation hole of a many-electron system, Phys. Rev. B 54 (1996) 16533-16539.

[66] A.D. Becke, Density-functional thermochemistry. IV. A new dynamic correlation functional and implications for exact-exchange mixing, J. Chem. Phys. 104 (1996) 1040-1046.

[67] J.M. Tao, J.P. Perdew, V.N. Staroverov, G.E. Scuseria, Climbing the density functional ladder: nonempirical meta-generalized gradient approximation designed for molecules and solids, Phys. Rev. Lett. $91(2003) 146401$.

[68] Y. Zhao, D.G. Truhlar, The M06 suite of density functionals for main group thermochemistry, thermochemical kinetics, noncovalent interactions, excited states, and transition elements: two new functionals and systematic testing of four M06-class functionals and 12 other functionals, Theor. Chem. Acc. 120 (2008) 215-241.

[69] T. Yanai, D. Tew, N. Handy, A new hybrid exchange-correlation functional using the Coulombattenuating method (CAM-B3LYP), Chem. Phys. Lett. 393 (2004) 51-57.

[70] J.-D. Chai, M. Head-Gordon, Long-range corrected hybrid density functionals with damped atom-atom dispersion corrections, Phys. Chem. Chem. Phys. 10 (2008) 6615-6620.

[71] M. Barysz, Y. Ishikawa, Relativistic Methods for Chemists, Springer, New York, 2010.

[72] H. Stoll, B. Metz, M. Dolg, Relativistic energy-consistent pseudopotentials -recent developments, J. Comput. Chem. 23 (2002) 767-778.

[73] M. Dolg, H. Stoll, A. Savin, H. Preuss, Energy-adjusted pseudopotentials for the rare earth elements, Theor. Chim. Acta 75 (1989) 173-194.

[74] M. Dolg, H. Stoll, H. Preuss, Energy-adjusted ab initio pseudopotentials for the rare earth elements, J. Chem. Phys. 90 (1989) 1730-1734.

[75] J. Yang, M. Dolg, Valence basis sets for lanthanide 4f-in-core pseudopotentials adapted for crystal orbital ab initio calculations, Theor. Chem. Acc. 113 (2005) 212-224.

[76] A. Weigand, X. Cao, J. Yang, M. Dolg, Quasirelativistic f-in-core pseudopotentials and corepolarization potentials for trivalent actinides and lanthanides: molecular test for trifluorides, Theor. Chem. Acc. 126 (2010) 117-127.

[77] M. Huelsen, A. Weigand, M. Dolg, Quasirelativistic energy-consistent 4f-incore pseudopotentials for tetravalent lanthanide elements, Theor. Chem. Acc. 122 (2009) 23-29.

[78] J.F. Stanton, J. Gauss, A discussion of some problems associated with the quantum mechanical treatment of open-shell molecules, Adv. Chem. Phys. 125 (2003) 101-146.

[79] A. Montoya, T.N. Truong, A.F. Sarofim, Spin contamination in Hartree-Fock and density functional theory wavefunctions in modeling of adsorption on graphite, J. Phys. Chem. A 104 (2000) 6108-6110. 
[80] T. Kupka, B. Ruscic, R.E. Botto, Toward Hartree-Fock- and density functional complete basis-setpredicted parameters, J. Phys. Chem. A 106 (2002) 10396-10407.

[81] D.G. Truhlar, Basis-set extrapolation, Chem. Phys. Lett. 294 (1998) 45-48.

[82] Y. Zhao, D.G. Truhlar, Infinite-basis calculations of binding energies for the hydrogen bonded and stacked tetramers of formic acid and formamide and their use for validation of hybrid DFT and ab initio methods, J. Phys. Chem. A 109 (2005) 6624-6627.

[83] B. Ramachandran, P. Kharidehal, L.M. Pratt, S. Voit, F.N. Okeke, M. Ewan, Computational strategies for reactions of aggregated and solvated organolithium carbenoids, J. Phys. Chem. A 114 (2010) 8423-8433.

[84] J.A. Pople, M. Head-Gordon, K. Raghavachari, Quadratic configuration interaction. A general technique for determining electron correlation energies, J. Chem. Phys. 87 (1987) 5968-5975.

[85] J. Tomasi, B. Mennucci, R. Cammi, Quantum mechanical continuum solvation models, Chem. Rev. 105 (2005) 2999-3093.

[86] R. Tripier, C. Platas-Iglesias, A. Boos, J.F. Morfin, L. Charbonniére, Towards fluoride sensing with positively charged lanthanide complexes, Eur. J. Inorg. Chem. 18 (2010) 2735-2745.

[87] C. Cossy, L. Helm, D.H. Powell, A.E. Merbach, A change in coordination number from nine to eight along the lanthanide(III) aqua ion series in solution: a neutron diffraction study, New J. Chem. 19 (1995) 2735.

[88] K. Djanashvili, C. Platas-Iglesias, J.A. Peters, The structure of the lanthanide aqua ions in solution as studied by ${ }^{17} \mathrm{O}$ NMR spectroscopy and DFT calculations, Dalton Trans. 5 (2008) 602-607.

[89] J. Ciupka, X. Cao-Dolg, J. Wiebke, M. Dolg, Computational study of lanthanide(III) hydration, Phys. Chem. Chem. Phys. 12 (2010) 13215-13223.

[90] C. Platas-Iglesias, L. Vaiana, D. Esteban-Gómez, F. Avecilla, J.A. Real, A. de Blas, T. Rodríguez-Blas, Electronic structure study of seven-coordinate first-row transition metal complexes derived from 1,10-diaza15-crown-5: a successful marriage of theory with experiment, Inorg. Chem. 44 (2005) 9704-9713.

[91] G.I. Csonka, J.P. Perdew, A. Ruzsinszky, Global hybrid functionals: a look at the engine under the hood, J. Chem. Theory Comput. 6 (2010) 3688-3703.

[92] P. Rydberg, L. Olsen, The accuracy of geometries for iron porphyrin complexes from density functional theory, J. Phys. Chem. A 113 (2009) 11949-11953.

[93] U. Cosentino, G. Moro, D. Pitea, L. Calabi, A. Maiocchi, Ab initio effective core potential calculations on lanthanide complexes: basis sets and electron correlation effects in the study of $\left[\mathrm{Gd}-\left(\mathrm{H}_{2} \mathrm{O}\right)_{9}\right]^{3+}$, J. Mol. Struct. (THEOCHEM) 392 (1997) 75-85.

[94] R.O. Freire, G.B. Rocha, A.M. Simas, Lanthanide complex coordination polyhedron geometry prediction accuracies of ab initio effective core potential calculations, J. Mol. Model. 12 (2006) 373-389.

[95] L. Maron, O. Eisestein, Do f electrons play a role in the lanthanide-ligand bonds? A DFT study of $\mathrm{Ln}\left(\mathrm{NR}_{2}\right)_{3} ; \mathrm{R}=\mathrm{H}, \mathrm{SiH}_{3}$, J. Phys. Chem. A 104 (2000) 7140-7143.

[96] D.J. Guillaumont, Quantum chemistry study of actinide(III) and lanthanide(III) complexes with tridentate nitrogen ligands, Phys. Chem. A 108 (2004) 6893-6900. 
[97] S.F. Sousa, E.S. Carvalho, D.M. Ferreira, I.S. Tavares, P.A. Fernandes, M.J. Ramos, J.A.N.F. Gomes, Comparative analysis of the performance of commonly available density functionals in the determination of geometrical parameters for zinc complexes, J. Comput. Chem. 30 (2009) 2752-2763.

[98] N.F. Bras, M.A.S. Perez, P.A. Fernandes, P.J. Silva, M.J. Ramos, Accuracy of density functionals in the prediction of electronic proton affinities of amino acid side chains, J. Chem. Theory Comput. 7 (2011) 38983908.

[99] H. Li, J.H. Jensen, Improving the efficiency and convergence of geometry optimization with the polarizable continuum model: new energy gradients and molecular surface tessellation, J. Comput. Chem. 25 (2004) 1449-1462.

[100] C. Platas-Iglesias, M. Mato-Iglesias, K. Djanashvili, R.N. Muller, L. Vander Elst, J.A. Peters, A. de Blas, T. Rodríguez-Blas, Lanthanide chelates containing pyridine units with potential application as contrast agents in magnetic resonance imaging, Chem. Eur. J. 10 (2004) 3579-3590.

[101] A. Barge, M. Botta, D. Parker, H. Puschmann, The nature of the counter-anion can determine the rate of water exchange in a metal aqua complex, Chem. Commun. 12 (2003) 1386-1387.

[102] J.A.K. Howard, A.M. Kenwright, J.M. Moloney, D. Parker, M. Woods, M. Por, M. Navet, O. Rousseau, Structure and dynamics of all of the stereoisomers of europium complexes of tetra(carboxyethyl) derivatives of dota: ring inversion is decoupled from cooperative arm rotation in the RRRR and RRRS isomers, Chem. Commun. 13 (1998) 1381-1382.

[103] M. Woods, G.E. Kiefer, S. Bott, A. Castillo-Muzquiz, C. Eshelbrenner, L. Michaudet, K. McMillan, S.D.K. Mudigunda, D. Ogrin, G. Tircsó, S. Zhang, P. Zhao, A.D. Sherry, Synthesis, relaxometric and photophysical properties of a new pH-responsive MRI contrast agent: the effect of other ligating groups on dissociation of a p-nitrophenolic pendant arm, J. Am. Chem. Soc. 126 (2004) 9248-9256.

[104] S. Aime, A.S. Batsanov, M. Botta, J.A.K. Howard, M.P. Lowe, D. Parker, Structure and relaxivity of macrocyclic gadolinium complexes incorporating pyridyl and 4-morpholinopyridyl substituents, New J. Chem. 23 (1999) 669-670.

[105] D. Chen, P.J. Squattrito, A.E. Martell, A. Clearfield, Synthesis and crystal structure of a ninecoordinate gadolinium(III) complex of 1,7,13-triaza-4,10,16-trioxacyclooctadecane- $\mathrm{N}, \mathrm{N}^{\prime}, \mathrm{N}^{\prime \prime}$-triacetic acid, Inorg. Chem. 29 (1990) 4366-4368.

[106] J. Wang, X.D. Zhang, W.G. Jia, Y. Zhang, Z.R. Liu, Syntheses and structural researches of ninecoordinated $\left(\mathrm{NH}_{4}\right)\left[\mathrm{Eu}^{\text {III }}(\right.$ Edta $\left.)\left(\mathrm{H}_{2} \mathrm{O}\right)_{3}\right] \cdot \mathrm{H}_{2} \mathrm{O}$ and $\left(\mathrm{NH}_{4}\right)_{3}\left[\mathrm{Eu}^{\text {III }}(\mathrm{Ttha})\right] \cdot 5 \mathrm{H}_{2} \mathrm{O}$, Russ. J. Coord. Chem. 30 (2004) 130-136.

[107] T.J. Caulfield, P. Guo, C.R. Illig, K.E. Kellar, E. Liversidge, J. Shen, J. Wellons, D. Ladd, N. Peltier, J.L. Toner, WIN 70197: a novel liver-targeted magnetic resonance imaging contrast agent, Bioorg. Med. Chem. Lett. 5 (1995) 1657-1662.

[108] R.K. Hocking, R.J. Deeth, T.W. Hambley, DFT study of the systematic variations in metal-ligand bond lengths of coordination complexes: the crucial role of the condensed phase, Inorg. Chem. 46 (2007) $8238-8244$. 